\title{
Interaction between FLASH and Lsm11 is essential for histone pre-mRNA processing in vivo in Drosophila
}

\author{
BRANDON D. BURCH, ${ }^{1}$ ASHLEY C. GODFREY, ${ }^{2}$ PAMELA Y. GASDASKA, ${ }^{3}$ HARMONY R. SALZLER, ${ }^{1}$ \\ ROBERT J. DURONIO, ${ }^{1,2,3}$ WILLIAM F. MARZLUFF, ${ }^{1,2,3,4}$ and ZBIGNIEW DOMINSKI ${ }^{3,4}$ \\ ${ }^{1}$ Curriculum in Genetics and Molecular Biology, University of North Carolina at Chapel Hill, Chapel Hill, North Carolina 27599, USA \\ ${ }^{2}$ Department of Biology, University of North Carolina at Chapel Hill, Chapel Hill, North Carolina 27599, USA \\ ${ }^{3}$ Program in Molecular Biology and Biotechnology, University of North Carolina at Chapel Hill, Chapel Hill, North Carolina 27599, USA \\ ${ }^{4}$ Department of Biochemistry and Biophysics, University of North Carolina at Chapel Hill, Chapel Hill, North Carolina 27599, USA
}

\begin{abstract}
Metazoan replication-dependent histone mRNAs are the only nonpolyadenylated cellular mRNAs. Formation of the histone mRNA 3' end requires the U7 snRNP, which contains Lsm10 and Lsm11, and FLASH, a processing factor that binds Lsm11. Here, we identify sequences in Drosophila FLASH (dFLASH) that bind Drosophila Lsm11 (dLsm11), allow localization of dFLASH to the nucleus and histone locus body (HLB), and participate in histone pre-mRNA processing in vivo. Amino acids 105154 of dFLASH bind to amino acids 1-78 of dLsm11. A two-amino acid mutation of dLsm11 that prevents dFLASH binding but does not affect localization of U7 snRNP to the HLB cannot rescue the lethality or histone pre-mRNA processing defects resulting from an $L s m 11$ null mutation. The last 45 amino acids of FLASH are required for efficient localization to the HLB in Drosophila cultured cells. Removing the first 64 amino acids of FLASH has no effect on processing in vivo. Removal of 13 additional amino acids of dFLASH results in a dominant negative protein that binds Lsm11 but inhibits processing of histone premRNA in vivo. Inhibition requires the Lsm11 binding site, suggesting that the mutant dFLASH protein sequesters the U7 snRNP in an inactive complex and that residues between 64 and 77 of dFLASH interact with a factor required for processing. Together, these studies demonstrate that direct interaction between dFLASH and dLsm11 is essential for histone pre-mRNA processing in vivo and for proper development and viability in flies.
\end{abstract}

Keywords: 3' end formation; histone locus body; histone mRNA

\section{INTRODUCTION}

The metazoan replication-dependent histone mRNAs are the only cellular mRNAs that are not polyadenylated (Marzluff et al. 2008). Instead, they end in a stem-loop sequence that has been conserved in evolution. Formation of mature histone mRNA requires only cleavage of the histone pre-mRNA to form the $3^{\prime}$ end. Cleavage is directed by two cis-elements: the stem-loop, which binds the stemloop binding protein (SLBP), and a purine-rich element known as the histone downstream element (HDE) that binds the U7 snRNP by base-pairing with the $5^{\prime}$ end of U7 snRNA (Mowry and Steitz 1987). Cleavage occurs between

Reprint requests to: Zbigniew Dominski, Program in Molecular Biology and Biotechnology, CB \#7100, University of North Carolina at Chapel Hill, Chapel Hill, NC 27599, USA; e-mail: dominski@med.unc.edu; fax: (919) 962-1273; or William F. Marzluff, Program in Molecular Biology and Biotechnology, CB \#7100, University of North Carolina at Chapel Hill, Chapel Hill, NC 27599, USA; e-mail: marzluff@med.unc.edu; fax: (919) 962-1273.

Article published online ahead of print. Article and publication date are at http://www.rnajournal.org/cgi/doi/10.1261/rna.2566811. these two cis-elements after recruitment of a cleavage factor containing the polyadenylation factors CPSF73, CPSF100, and Symplekin, as well as other unidentified components (Dominski et al. 2005; Kolev and Steitz 2005; Wagner et al. 2007; Kolev et al. 2008; Sullivan et al. 2009). How the cleavage factor is recruited to the processing site is not well understood. In Drosophila, both SLBP and the U7 snRNP are required for cleavage in vitro (Dominski et al. 2005) and in vivo (Sullivan et al. 2001; Lanzotti et al. 2002; Godfrey et al. 2006, 2009), suggesting that these factors participate in the recruitment of the cleavage factor to the pre-mRNA.

The U7 snRNP is comprised of U7 snRNA and a ring of $7 \mathrm{Sm}$ proteins. Two of these proteins, Lsm10 and Lsm11, are distinct from the canonical spliceosomal Sm proteins and replace SmD1 and SmD2, respectively (Pillai et al. 2001, 2003). With its extended N-terminal region, Lsm11 is much larger than other Sm proteins. This region is essential for processing (Pillai et al. 2003) and is thought to bind factors unique to histone pre-mRNA processing (Azzouz et al. 2005). There is one region within the first 40 amino acids of Lsm11 
that is conserved from Drosophila to mammals (Azzouz and Schümperli 2003), although its function is not known.

We identified human FLASH as a protein that binds the N-terminal half of Lsm11 in a yeast two-hybrid screen and also identified the Drosophila FLASH ortholog (Yang et al. 2009). FLASH is essential for processing histone pre-mRNA in Drosophila cultured cells and in nuclear extracts from mammalian cells. A small region at the $\mathrm{N}$ terminus of human FLASH contains all the sequences required for histone pre-mRNA processing in vitro (Yang et al. 2009). FLASH localizes to the histone locus body (HLB) (Barcaroli et al. 2006a; Yang et al. 2009), a nuclear organelle associated with the histone genes in both humans and Drosophila (Liu et al. 2006b; Bongiorno-Borbone et al. 2008; Ghule et al. 2008). The HLB contains the U7 snRNP and a number of other factors required for histone gene expression (Isogai et al. 2007; Wagner et al. 2007). The precise role of FLASH in processing is not understood, but it may participate in recruitment and/or activation of the cleavage factor.

At 1982 amino acids ( $200 \mathrm{kDa})$, mammalian FLASH is considerably larger than its Drosophila counterpart, which contains only 844 amino acids $(\sim 93 \mathrm{kDa})$. The region sharing the highest degree of conservation between the two proteins is located between amino acids 45 and 177 in dFLASH, which has $25 \%$ identity and $48 \%$ similarity with amino acids 30-169 of human FLASH. This region contains the binding site for the $\mathrm{N}$-terminal region of Lsm11 as determined in a yeast two-hybrid assay and in GST-pulldown experiments (Yang et al. 2009).

Here, we identify the critical amino acids required for the interaction between Drosophila FLASH (dFLASH) and Lsm11 (dLsm11). There is a small region of dFLASH required for binding to dLsm11, and we generated point mutations in dFLASH that abolish binding. A region in the first 40 amino acids of dLsm11, the most highly conserved in the protein, interacts with dFLASH. A two-amino acid mutation in dLsm11 that abolishes dFLASH binding in vitro was not able to rescue the lethality and histone pre-mRNA processing defects of an Lsm11 null mutant fly, indicating that the dFLASH/dLsm11 interaction is critical for viability. However, this interaction is not required for proper localization of either dFLASH or dLsm11 to the HLB in flies, indicating that misprocessing in the mutant flies does not occur due to mislocalization of these proteins. We also identify a region in the $\mathrm{N}$ terminus of dFLASH that likely binds a novel processing factor, and we show that there are sequences near the $\mathrm{C}$ terminus of the protein that are required for efficient localization of dFLASH to the nucleus and the HLB.

\section{RESULTS}

\section{Amino acids 105-154 of dFLASH are required for binding dLsm11}

We previously identified FLASH as a factor that binds to the N-terminal region of Lsm11 and demonstrated that a 139-amino acid N-terminal fragment of human FLASH was sufficient to support histone pre-mRNA processing in a nuclear extract from HeLa cells (Yang et al. 2009). To define the region of dFLASH that binds dLsm11, we constructed the series of dFLASH deletion mutants shown in Figure 1A. Each mutant was cloned into a vector encoding an N-terminal glutathione-S-transferase (GST) cassette to test binding with Lsm11. For these assays, ${ }^{35} \mathrm{~S}$-labeled dLsm11 or dFLASH was synthesized by in vitro translation, incubated with the recombinant GST-fusion proteins, and the bound proteins were detected by autoradiography.

Deleting amino acids $1-66,1-77$, or 1-104 from the N terminus of dFLASH had no effect on binding to dLsm11 (Fig. 1B, lanes 3,4; Fig. 1D, lane 3), demonstrating that the binding region lies downstream from residue 104. Removal of residues 1-121 resulted in greatly reduced binding (Fig. $1 \mathrm{D}$, lane 4 ), and removal of residues $1-140$ or $1-165$ completely abolished the ability of dFLASH to bind dLsm11 (Fig. 1D, lanes 5,6, respectively), indicating that these regions contain residues that are important for binding dLsm11, either through direct binding contacts with dLsm11 or through some effect on the structure of dFLASH.

Deletions were made from the $\mathrm{C}$ terminus of dFLASH 1178, removing amino acids C-terminal from residues 154, 143,137 , and 131. Removal of amino acids $155-178$ had no effect on binding (Fig. 1B, lane 5). Further deletion from the $\mathrm{C}$ terminus of dFLASH to amino acid 143, 137, or 131 revealed that amino acids $1-143$ of dFLASH bound dLsm11 with lower affinity (Fig. 1C, lane 12) and that $1-137$ or 1-131 did not bind dLsm11 (Fig. 1C, lanes 9,6, respectively). These two sets of deletion mutants demonstrate that the critical region in dFLASH for binding dLsm11 lies between amino acids 105 and 154 .

To define the binding site more precisely, we designed a number of point mutations based on areas within amino acids 105-154 of dFLASH that were most similar to human FLASH (Fig. 2A) and determined if ${ }^{35}$ S-labeled dFLASH could bind GST-dLsm11 (Fig. 2B). Mutation of dFLASH residues to alanines, N125A/L126A or L129A/L130A, abolished binding to GST-dLsm11 (Fig. 2B, lanes 6,9, respectively). Mutation of another conserved residue, E136, to alanine (E136A) resulted in slightly reduced binding to GST-dLsm11 (Fig. 2B, lane 21). This result was reproducible, although the effect of this mutation was not as strong as that of the N125A/L126A and L129A/L130A mutations. In contrast, T132A, K134A, R139A/K140A, E141A, I144A, or L147A mutations (Fig. 2B, lanes 12,18,24,30,33,36) had no significant effect on binding compared to wild type (Fig. $2 \mathrm{~B}$, lane 3 ). To confirm our findings, we did the reciprocal experiment in which we expressed GST-tagged dFLASH proteins harboring N125A/L126A or L129A/L130A mutations and tested their ability to bind ${ }^{35}$ S-labeled dLsm 11 . Neither of these mutant proteins was able to bind dLsm11 (Fig. 2C, lanes 4,5). Together, these results demonstrate that there is a region in dFLASH between amino acids 125 
A

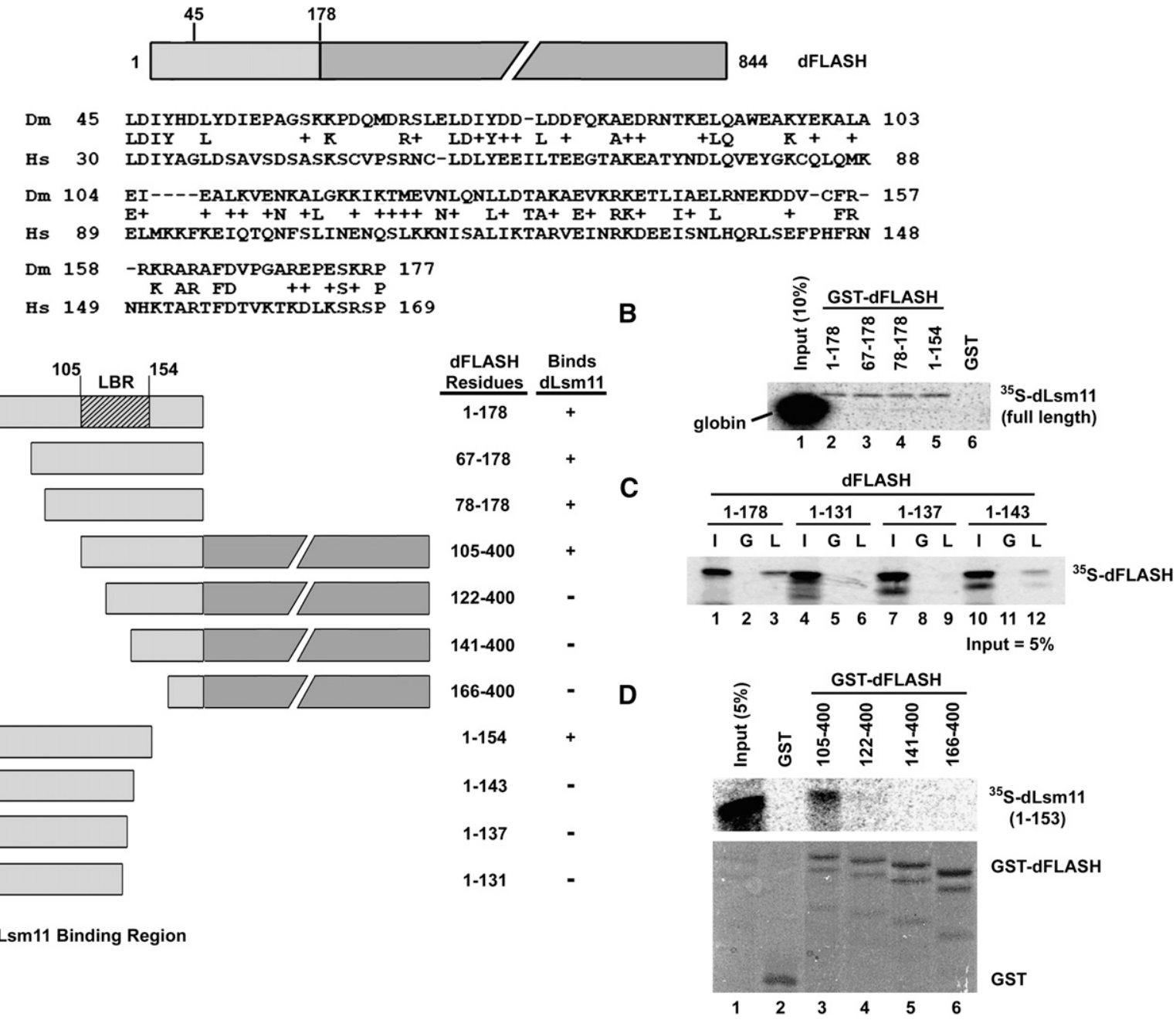

FIGURE 1. Region of dFLASH that binds dLsm11. (A) A diagram of the FLASH protein and deletion mutants is shown, together with the sequence alignment of FLASH between flies and mammals. The hatched region, LBR, indicates the Lsm11 binding site. The ability of each mutant to bind dLsm11, determined in panels $B-D$, is shown. (+) Binding; (-) failure to bind. (B) GST-pulldown of ${ }^{35}$ S-labeled full-length dLsm11, synthesized in a reticulocyte lysate, with the indicated GST-dFLASH fusion proteins (lanes 2-5). The input (lane 1) is partially obscured by endogenous globin. (C) GST-pulldown with ${ }^{35}$ S-labeled dFLASH proteins, synthesized in a wheat germ lysate, with a GST-dLsm11 fusion protein containing the first 153 amino acids of dLsm11. The multiple bands in some of the ${ }^{35}$ S-FLASH proteins are a result of initiation at internal methionines. (I) Input; (G) GST alone; (L) GST-dLsm11. (D) GST-pulldown assay in which ${ }^{35}$ S-labeled dLsm11 (AA1-153), synthesized in a wheat germ lysate, was combined with the GST-dFLASH proteins shown. A Coomassie stain of the SDS gel, used to monitor the amount of GST protein pulled down in the assay, is shown below. The multiple stained bands (lanes 3-6) are proteolytic fragments that removed C-terminal fragments of FLASH.

and 130 that is essential for binding dLsm11 and that the conserved E136 is also required for maximal binding.

\section{Conserved residues within the $\mathbf{N}$ terminus of dLsm11 bind dFLASH}

To define the residues of dLsm11 that bind dFLASH, we created deletion and point mutants (Fig. 3A) of dLsm 11 and tested their ability to bind dFLASH using GSTpulldown assays. We had previously shown that deleting the first 40 amino acids of Lsm 11 abolishes the ability of both human and Drosophila FLASH to bind human Lsm11 (Yang et al. 2009). We determined a minimal region of dLsm11 required for binding to dFLASH. A fragment containing amino acids 1-54 of dLsm11 (Fig. 3B, lane 6) did not bind dFLASH, while all fragments containing at least the first 78 amino acids were able to bind dFLASH (Fig. 3B, lanes 1-5). These results indicate that residues $1-40$, while necessary, are not sufficient for binding.

Within the first 78 amino acids of dLsm11, there is a region (amino acids 20-36 in dLsm11; 24-40 in hLsm11) that is well-conserved from mammals to flies (Azzouz and Schümperli 2003), with 12 of the 17 amino acids being identical (Fig. 3A). No factors that interact with this region have been described. We made a number of point mutations 
A

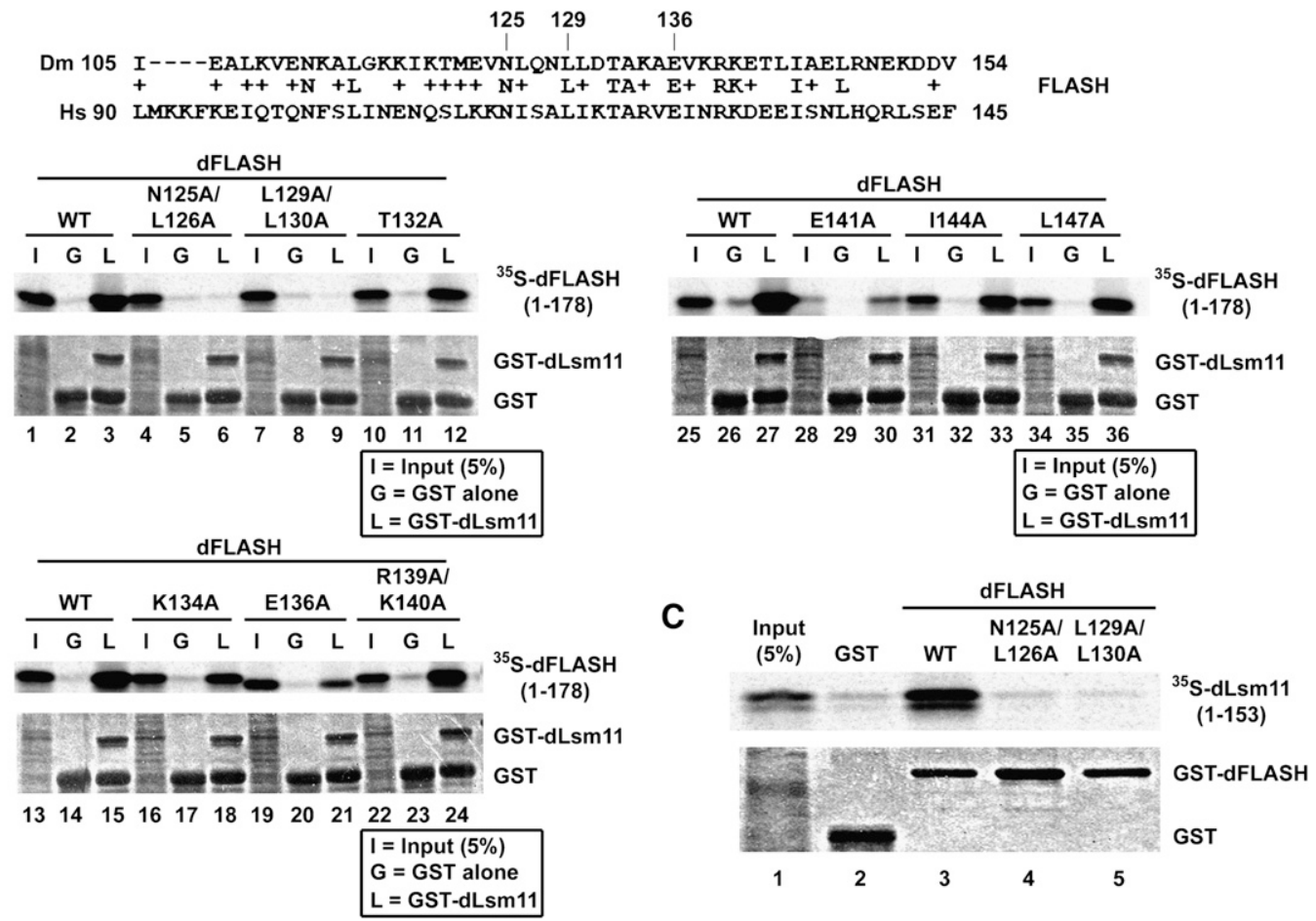

FIGURE 2. Conserved residues within the $\mathrm{N}$ terminus of dFLASH are required for binding dLsm11. (A) Sequence comparison of the region of Drosophila and human FLASH required for binding dLsm11, as determined in panels $B$ and $C$. The positions of point mutations that affected binding to dLsm11 are indicated above the sequence. (B) GST-pulldown assay in which ${ }^{35}$ S-labeled dFLASH point mutant proteins (AA1-178), synthesized in a wheat germ lysate, were incubated with wild-type GST-dLsm11 (AA1-153). A Coomassie stain of the gel is shown below. (I) Input; (G) GST alone; (L) GST-dLsm11. The GST contaminating the fusion proteins (as a result of proteolysis during expression of the proteins) did not affect the analysis. (C) GST-pulldown assay in which ${ }^{35}$ S-labeled dLsm11 (AA1-153) was incubated with the indicated GST-dFLASH protein (AA1-178; lanes 3-5) is shown. A Coomassie stain of the gel is shown below.

(Fig. 3A) to test whether these conserved residues are required for binding dFLASH. The F27A/N28A mutant eliminated the interaction between $\mathrm{dLsm} 11$ and the N-terminal 178 amino acids of dFLASH (Fig. 3C, lane 6), while S24A/D25A, P29A/L30A, or P36A/N37A mutations had no effect on binding (Fig. 3C, lanes 5,7,8). We also tested the ability of these mutants to bind the full length dFLASH protein and obtained the same result (Fig. 3D, lanes 4-6), indicating that the FN residues at positions 27 and 28 of Lsm11 are critical for the binding interaction between dFLASH and dLsm11.

We carried out the same analysis using a GST-dFLASH fusion protein (AA1-178) and ${ }^{35}$ S-labeled-wild type and mutant dLsm11. In addition to the mutations described above, we tested two additional mutations, L20A/D21A/ $\mathrm{V} 22 \mathrm{~A}$ and $\mathrm{L} 33 \mathrm{~A} / \mathrm{Y} 34 \mathrm{~A}$. This experiment confirmed the finding that the FN residues at positions 27 and 28 are critical for binding (Fig. 3E, lane 12) and revealed that mutation of the amino acids at positions 20-22 also dramatically reduced dFLASH binding (Fig. 3E, lane 6). Mutation of the LY residues at positions 33 and 34 resulted in reduced binding, albeit to a lesser degree than was observed for the other two mutations (Fig. 3E, lane 21).

\section{The interaction between dLsm11 and dFLASH is required for histone pre-mRNA processing and viability in flies}

There is a single cluster of histone genes in Drosophila comprised of about 100 copies of a tandemly repeated 4.5$\mathrm{kB}$ unit, with each unit containing one copy of each of the five histone genes (Lifton et al. 1978). Downstream from the HDE in each of the Drosophila histone genes are cryptic polyadenylation signals. When histone pre-mRNA processing is prevented by mutation or depletion of a factor required for processing, histone mRNAs are still expressed, but they are polyadenylated. Previously, we have shown that flies with null mutations in SLBP, U7 snRNA, Lsm10 or $L s m 11$ produce $>90 \%$ polyadenylated histone mRNAs (Sullivan et al. 2001; Lanzotti et al. 2002; Godfrey et al. 2006, 2009). U7 snRNA mutants are viable, but sterile and do not start producing polyadenylated histone mRNA until the third instar larval stage, since the maternally loaded dU7 snRNP persists into this developmental stage (Godfrey et al. 2006). In contrast, Slbp mutants are lethal, with production of polyadenylated histone mRNA starting early in embryogenesis (Sullivan et al. 2001; Lanzotti et al. 2002). Null mutations in either Lsm10 or Lsm11 are also lethal, 
A
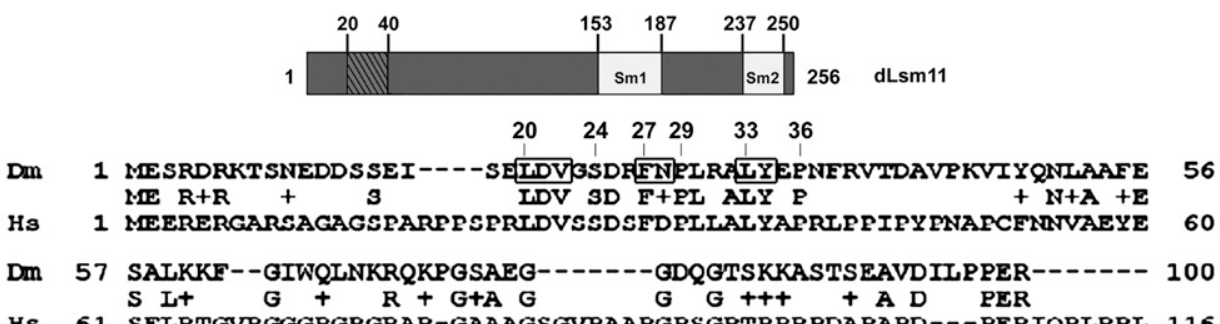

Hs

61 SFLRTGVRGGGRGRGRAR-GAAAGSGVPAAPGPSGRTRRRPDAPAPD---PERIQRIRRL 116
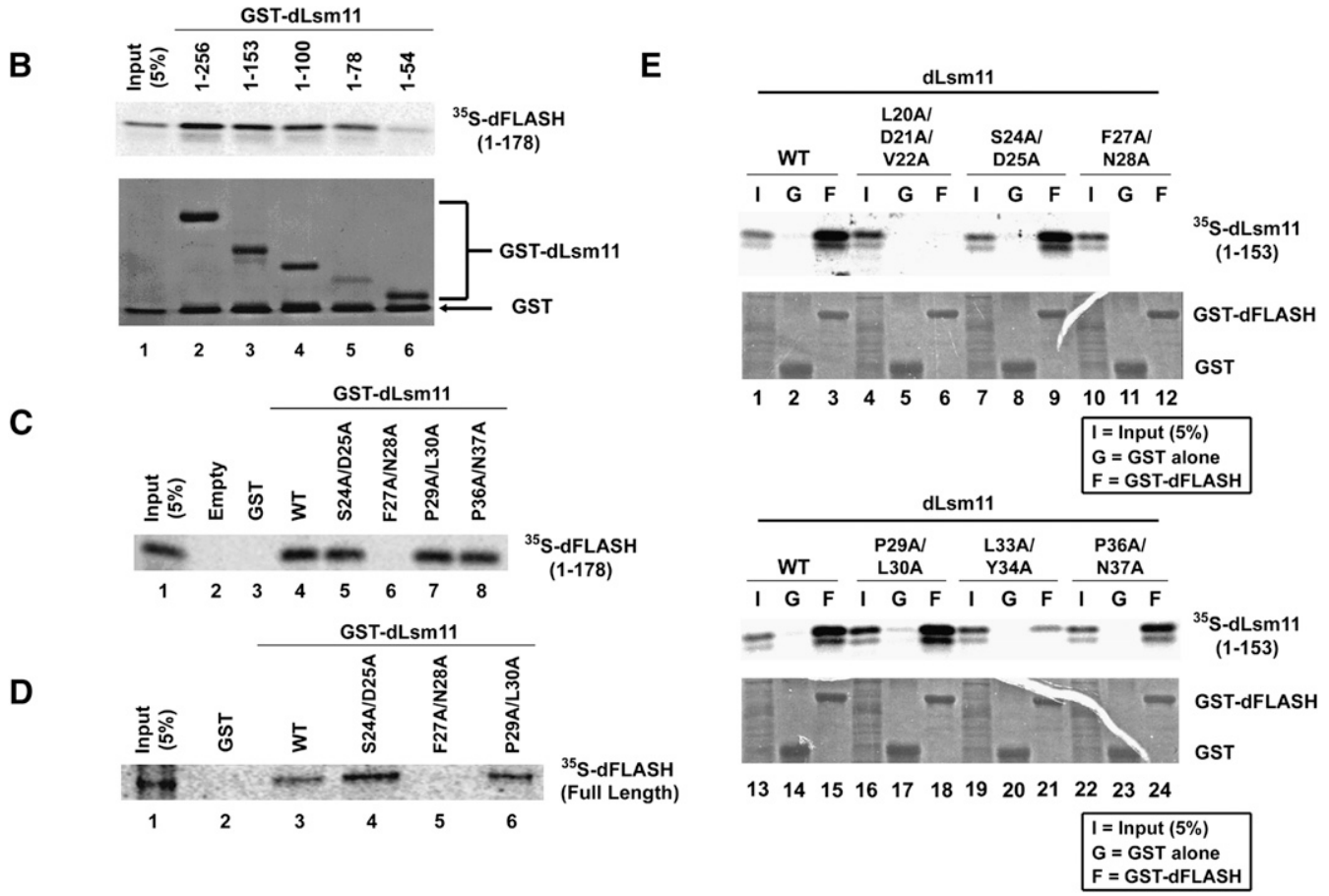

FIGURE 3. Conserved residues within the $\mathrm{N}$ terminus of dLsm11 are required for binding dFLASH. (A) Model of dLsm11 showing the Sm domains and the region required for dFLASH binding, together with the alignment of the N-terminal region of dFLASH and human FLASH. The residues mutated and tested for dFLASH binding (hatched region between amino acids 20 and 40) are indicated above the sequence. Residues involved in binding dFLASH are boxed. (B) GST-pulldown assay in which ${ }^{35}$ S-labeled dFLASH protein (AAl-178), synthesized in a wheat germ extract, was incubated with GST-dLsm11 full length (lane 2) or C-terminal deletion proteins (lanes 3-6). A Coomassie stain of the gel is shown below. The GST-Lsm11 proteins contain a substantial amount of free GST as a result of proteolysis in the bacteria, which has no effect on the binding assay. (C) GST-pulldown assay in which ${ }^{35}$ S-labeled dFLASH protein (AA1-178) was incubated with GST (lane 3), wild-type GSTdLsm11 full length protein (lane 4), or the indicated mutants (lanes 5-8); where the indicated residues were changed to alanines is shown. (D) GST-pulldown assay in which ${ }^{35}$ S-labeled full length dFLASH protein was incubated with GST (lane 2) or the indicated full length GST-dLsm11 fusion proteins (lanes 3-6). (E) GST-pulldown assay in which the wild-type (lanes $1-3$ ) or indicated mutant ${ }^{35}$ S-labeled dLsm 11 proteins (AA1153 ) were incubated with GST (lanes $G$ ) or wild-type GST-dFLASH protein (AA1-178, lanes $F$ ). $5 \%$ of the input is shown in lanes $I$. A Coomassie stain of each gel is shown below.

with mutants failing to eclose and dying as nonpharate pupae (Godfrey et al. 2009). In these mutants, polyadenylated histone mRNAs are observed at the same stage of development as for the U7 snRNA mutants. Because these mutants share the same molecular phenotype as the U7 snRNA mutants but exhibit a more severe developmental phenotype, it was hypothesized that this difference may indicate another essential role for Lsm10 and Lsm11 in addition to their requirement for histone pre-mRNA processing (Godfrey et al. 2009).

We tested whether mutations of the dFLASH binding site in dLsm11 would affect dLsm11 function in vivo by testing the ability of two of the Lsm11 point mutants to rescue a null mutant of Lsm11 (Godfrey et al. 2009). We created rescue transgenes encoding wild-type dLsm11, dLsm11 S24A/D25A, which showed normal binding to dFLASH, and dLsm11 F27A/N28A, which did not bind dFLASH. These transgenes, encoding V5-tagged wild-type or mutant Lsm11 driven by the endogenous Lsm11 promoter, were each inserted into the same site in the Drosophila genome on chromosome 2 using the phiC31 integration system (Groth et al. 2004). The S24A/D25A mutant rescued the lethality of the Lsm11 null mutant, as did the wild-type V5-tagged dLsm11. Furthermore, the 
eclosed flies were fertile. In contrast, the F27A/N28A mutant did not rescue the Lsm11 null mutant lethality. Thus, binding to dFLASH is an essential function of dLsm11.

We tested whether the dLsm11 mutant transgenes could restore normal $3^{\prime}$ end processing of histone mRNA, since the Lsm11 null mutant produces almost exclusively polydenylated histone mRNA. Northern blot analysis of histone H3 mRNA demonstrated that the V5-tagged wild-type and S24A/D25A mutant dLsm11 transgenes restored normal processing of histone mRNA to a similar extent $(\sim 30 \%$ of wild type [WT] levels) in late third instar larvae, although some misprocessed mRNA was still observed (Fig. 4A, lanes $3,5)$. Similar results were previously obtained with rescue of the U7 snRNA (Godfrey et al. 2006) and SLBP mutants (Lanzotti et al. 2002). In contrast, the dLsm11 F27A/N28A mutant did not restore histone $\mathrm{H} 3$ mRNA processing (Fig. $4 \mathrm{~A}$, lane 4). The failure of WT and S24A/D25A dLsm11 transgenes to rescue histone pre-mRNA processing fully is likely due to lower levels of expression from these transgenes compared to the Lsm11 rescue construct analyzed previously (Godfrey et al. 2009).

\section{The mutant Lsm11 proteins localize to the HLB}

Based upon these results, it was possible that the histone pre-mRNA misprocessing phenotype exhibited by the
F27A/N28A mutant might reflect a failure to recruit dLsm11, dFLASH, or both to the HLB, if recruitment depends on the interaction between these two proteins. Examination of salivary glands from wandering third instar larvae stained with antibodies against Mute, a known HLB component (Bulchand et al. 2010), and V5, which recognizes the V5 epitope of the exogenous dLsm11 proteins, revealed that each dLsm11 mutant protein localized to the HLB just as well as wild-type dLsm11 (Fig. 4B). This result demonstrates that dLsm11, and thus U7 snRNP, is recruited to the HLB in a manner that does not require the interaction of the $\mathrm{N}$ terminus of Lsm11 and FLASH. We also tested the alternative possibility, that dFLASH might be recruited to the HLB by U7 snRNP. We found that dFLASH localizes to the HLB in Lsm11 null flies just as well as it does in wild-type flies (Fig. 4C). Together, these data reveal that neither dFLASH nor dLsm11 is solely responsible for recruiting the other to the HLB.

\section{The $\mathbf{N}$ terminus of $\mathbf{d F L A S H}$ is not required for localization to the histone locus body}

FLASH localizes to the HLB in both mammals and flies, based upon colocalization with NPAT in mammals (Barcaroli et al. 2006b) and Mute (Fig. 4), MPM-2 and Lsm11 in flies (Yang et al. 2009). Immunofluorescence experiments were used to identify the portions of dFLASH required for its

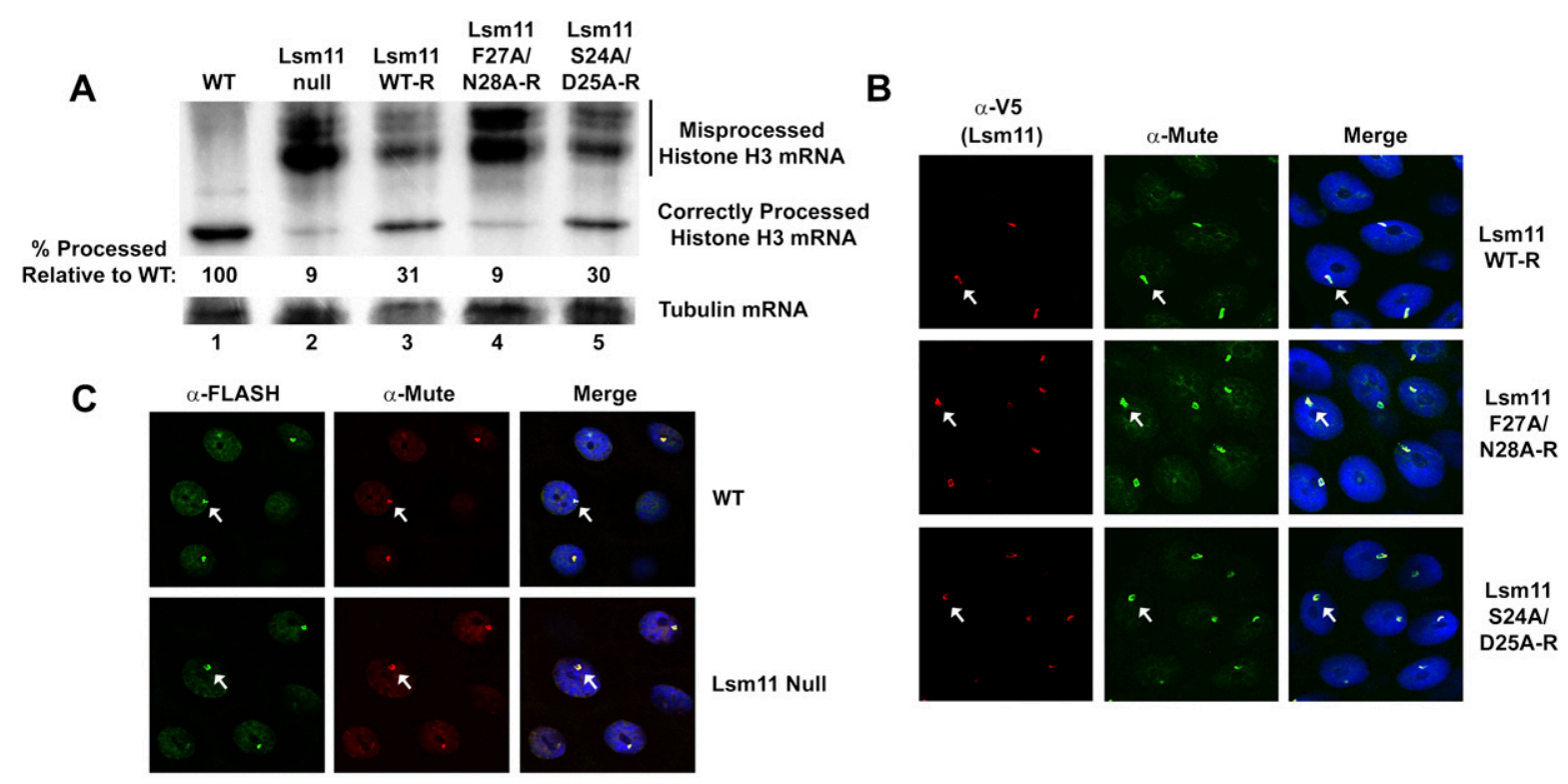

FIGURE 4. Effect of expression of dLsm11 mutant proteins in Lsm11 null flies. (A) Northern blot analysis of histone H3 mRNA in total RNA from third instar larvae of wild type (lane 1), Lsm11 null (lane 2) and Lsm11 rescue (R) strains using WT-Lsm11 (lane 3), the F27A/N28A mutant (lane 4), or the S24A/D25A mutant (lane 5). Tubulin mRNA was used as a loading control. Values of percent-processed-histone H3 mRNA are indicated. (B) Confocal microscopy images of wandering third instar larval salivary glands from lines containing the indicated V5-Lsm11 transgenes were stained using antibodies against V5 and Mute (Bulchand et al. 2010), which localizes to the HLB. DNA is indicated by DAPI staining (blue). Lsm11 colocalizes with Mute at the HLB in all three genotypes, indicated by white arrows. $(C)$ Confocal microscopy images of wild type and Lsm11 null salivary glands from wandering third instar larvae, stained using antibodies against FLASH and Mute, with DNA indicated by DAPI staining (blue). FLASH colocalizes with Mute at the HLB in both genotypes, indicated by white arrows. 
localization to the HLB. We constructed V5-epitope-tagged dFLASH deletion constructs (Fig. 5A) driven by the dFLASH promoter, expressed these constructs in Drosophila cultured cells, and used immunofluorescence against the V5 epitope to determine localization of the recombinant proteins. To detect the HLB, we used antibodies against Mute (Bulchand et al. 2010) or Mxc/dNPAT (White et al. 2011), both newly discovered components of the Drosophila HLB. Note that in these experiments the transfected dFLASH-V5 proteins may compete or cooperate with the normal amounts of wild-type dFLASH present in the cells for HLB localization. The V5-tagged full-length dFLASH (1-844) localized to the HLB (Fig. 5B), as did dFLASH 105844 (Fig. 5B), as well as smaller N-terminal deletions (Supplemental Fig. S1), indicating that the first 104 residues of the protein are not required for localizing dFLASH to the HLB. Deletion of the $\mathrm{N}$ terminus, including the dLsm 11 binding site (FLASH 166-844), did not prevent dFLASH localization to the HLB (Figs. 5B and 6C) but did result in some of the mutant dFLASH being distributed throughout the nucleoplasm in a subset of cells (Fig. 5B). This suggests that this region, while not being essential for recruiting
dFLASH to the HLB, may help stabilize its association there. We also found that the dLsm11 binding site is not itself sufficient for efficient localization of dFLASH to the HLB, since proteins containing only amino acids $1-169$ or 1-289 show a mostly diffuse staining pattern throughout the nucleus, with only a limited ability to localize to the HLB (Fig. 5C). Since these proteins specifically localize to the nucleus, there must exist a nuclear localization signal within the first 170 amino acids.

\section{The last 45 amino acids of dFLASH are essential for localization to the histone locus body}

We created additional deletion constructs of dFLASH (Fig. 6A), which also had a V5 tag at the C terminus. Deletion of the last 45 amino acids from dFLASH results in mislocalization of most of the protein into the nucleoplasm, although a small portion of this protein can localize to the HLB (Fig. 6B), most likely due to the weak ability of the $\mathrm{N}$ terminus of dFLASH to promote recruitment to the HLB. Further deletion of the $\mathrm{C}$ terminus to amino acid 757 or 733 resulted in an identical distribution pattern in the

A

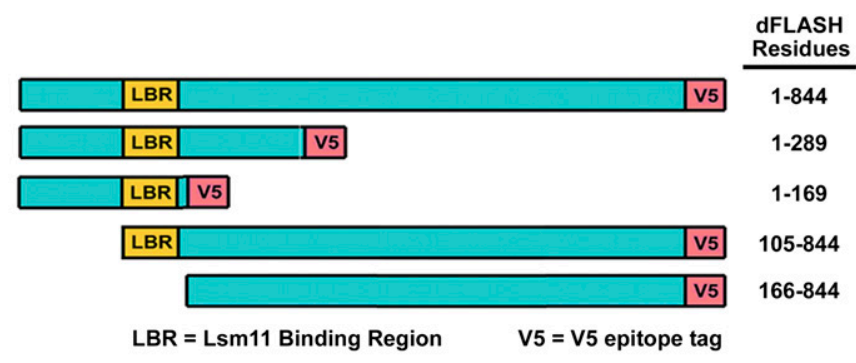

B
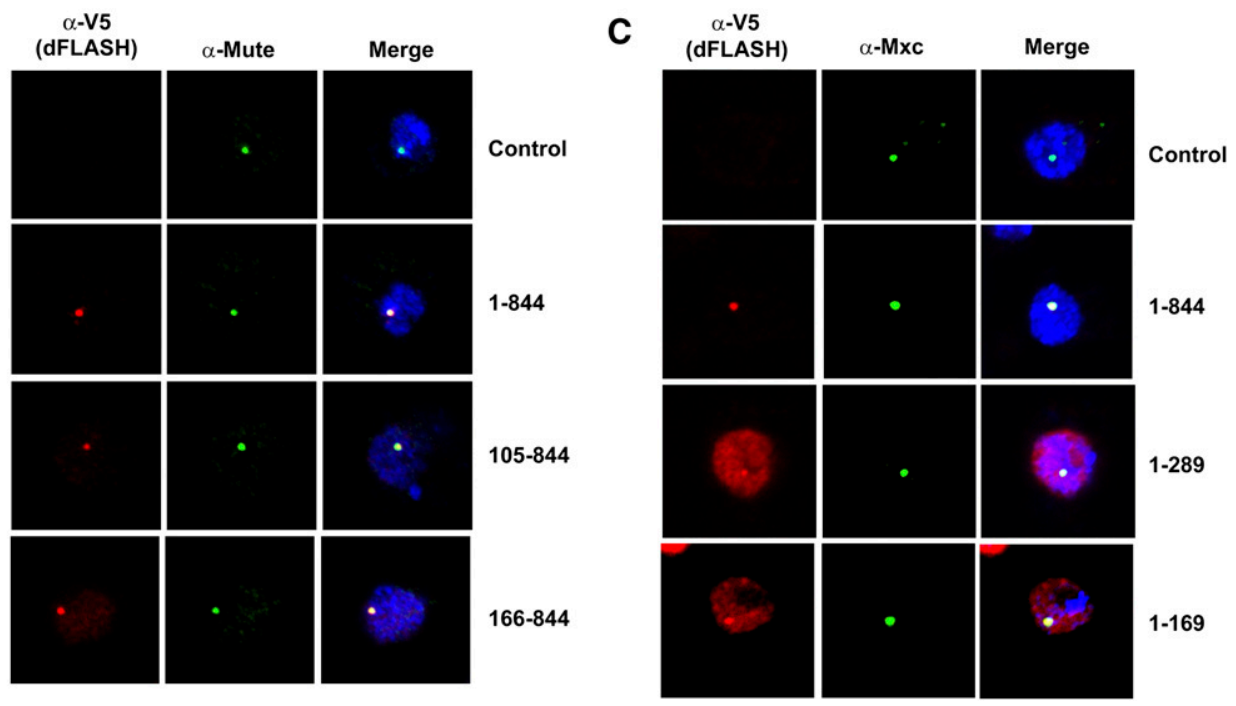

FIGURE 5. The N-terminal region of dFLASH is not required for localization of dFLASH to the Histone Locus Body. (A) Diagram of dFLASH deletion constructs, with the Lsm11 binding site (LBR) indicated. $(B, C)$ Drosophila D.Mel-2 cells were transfected with the dFLASH full length and deletion constructs and stained with antibodies against the V5 epitope, recognizing recombinant dFLASH, and Mute or Mxc, which localize to the HLB in Drosophila. For each panel, cells were transfected with the indicated clones and then stained and imaged at the same time, with the same exposure time. Each panel also shows DAPI staining used to stain the nucleus. Representative images are shown. 
A
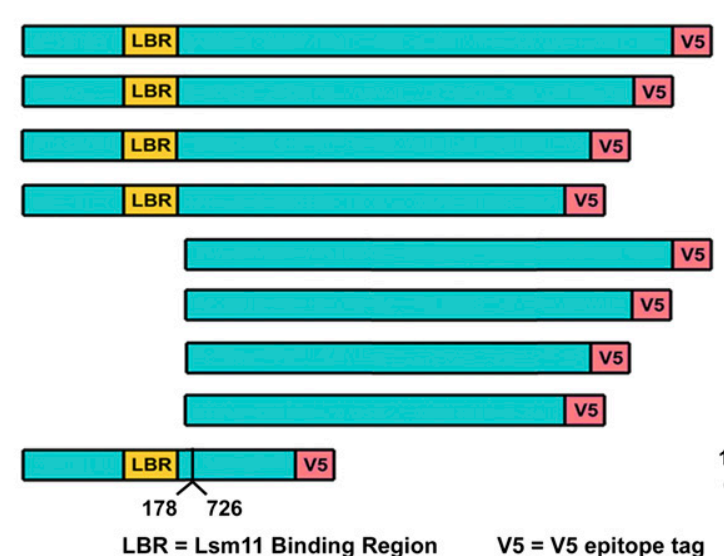

LBR $=$ Lsm11 Binding Region

V5 $=$ V5 epitope tag

B
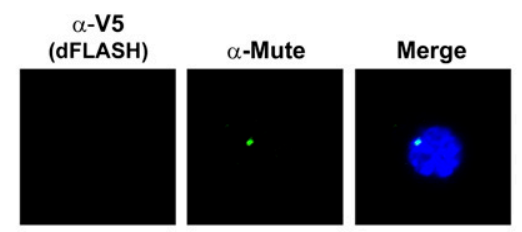

Control
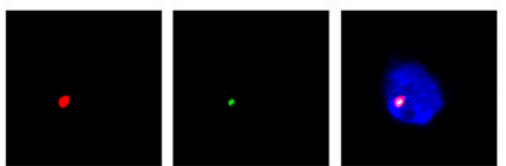

$1-844$
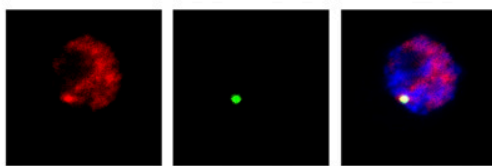

$1-799$
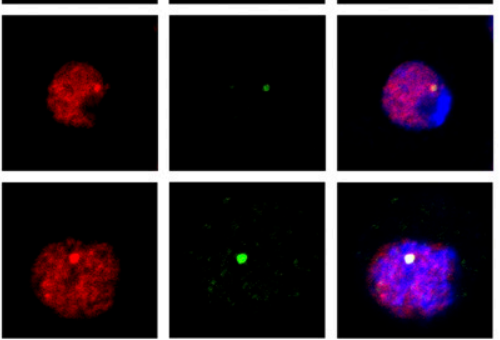

dFLASH

Residues

$1-844$

1-799

$1-757$

$1-733$

166-844

166-799

166-757

166-733

1-178/726-844 (miniFLASH)
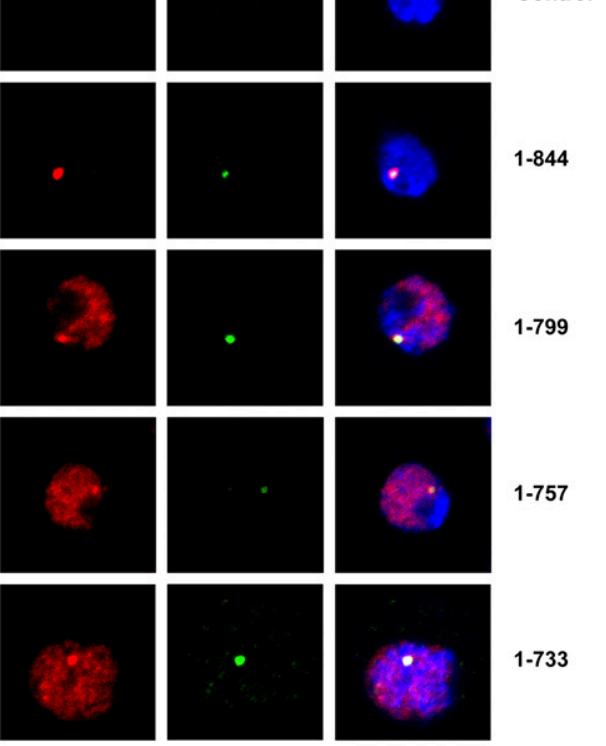

1-757

$1-733$
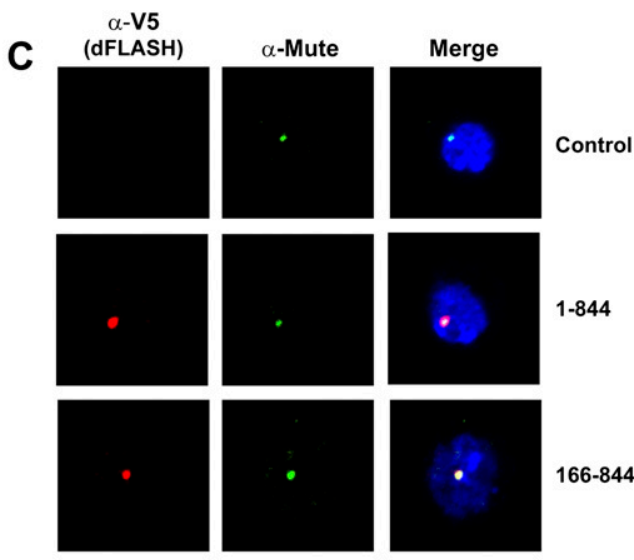

166-844
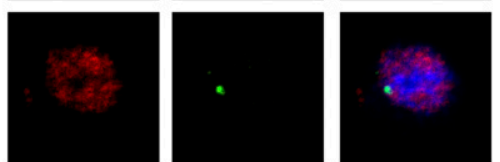

166-799
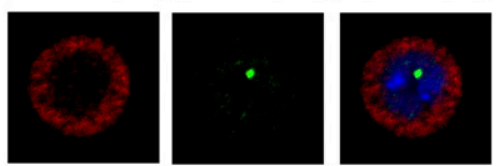

166-757
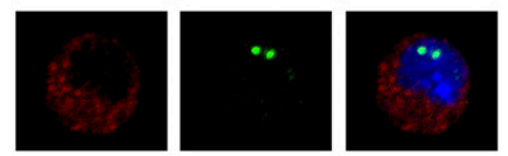

$166-733$

$\alpha-\mathrm{V} 5$
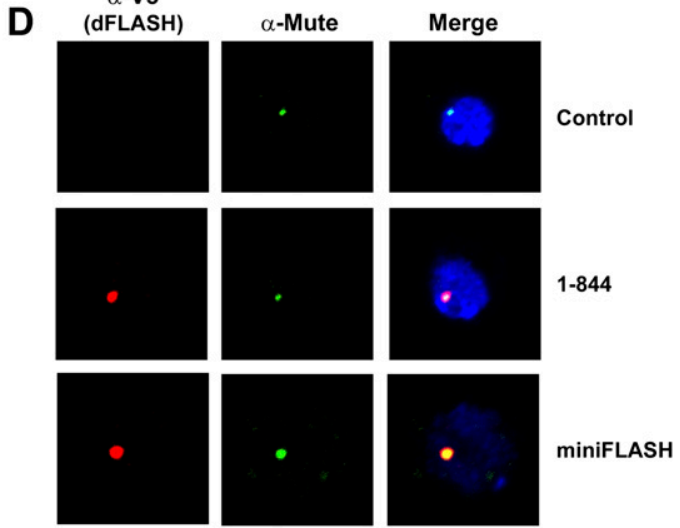

FIGURE 6. The $\mathrm{C}$ terminus of dFLASH is required for localization of dFLASH to the Histone Locus Body. (A) Diagram of dFLASH deletion constructs. $(B-D)$ Drosophila D.Mel-2 cells were transfected with the indicated constructs and stained with antibodies against V5, recognizing recombinant dFLASH, and Mute, which localizes to the HLB. The nucleus is indicated by DAPI staining of DNA. For each panel, cells were transfected with the indicated clones and then stained and imaged at the same time, with the same exposure time.

nucleoplasm, again with some of the protein able to localize to the HLB (Fig. 6B).

Based upon our observation that deletion of the $\mathrm{N}$ terminus of dFLASH had little effect on the ability of the protein to localize to the HLB, we created several deletion constructs encoding dFLASH proteins with their $\mathrm{N}$ terminus deleted along with progressively larger deletions of the $\mathrm{C}$ terminus of the protein (Fig. 6A). Simultaneous deletion of the first 166 amino acids from the $\mathrm{N}$ terminus and the last 45 amino acids of the $\mathrm{C}$ terminus of dFLASH resulted in complete mislocalization of the protein into the nucle- oplasm, with no observed concentration at the HLB (Fig. $6 \mathrm{C})$. This suggests the presence of a sequence within the last 45 amino acids of the protein that is required for HLB localization. This sequence likely constitutes a contact point for an unknown interaction partner of dFLASH that is responsible for the primary recruitment of dFLASH to the HLB. Further deletions of dFLASH to amino acid 757 or 733 not only prevented localization to the HLB but led to complete exclusion of the protein from the nucleus (Fig. 6C). These results indicate that there is a second nuclear localization signal in dFLASH that is located between residues 758 and 
799 which, in combination with a sequence in the first 170 amino acids of the $\mathrm{N}$ terminus of the protein, is responsible for import of dFLASH into the nucleus.

To determine whether the central region of dFLASH plays any role in localizing dFLASH, we created a construct encoding a V5-tagged dFLASH protein in which the N-terminal 178 amino acids are directly fused to the C-terminal 119 amino acids of the protein (Fig. 6A). This protein, which we named mini-FLASH, is recruited to the HLB as efficiently as the wild-type protein (Fig. $6 \mathrm{D})$. These results indicate that the $\mathrm{N}$-terminal 178 amino acids and the C-terminal 119 amino acids are sufficient for localizing to the HLB.

\section{The first 64 amino acids of dFLASH are dispensable for histone pre-mRNA processing in Drosophila cultured cells}

We have developed reporter genes that allow us to assess histone pre-mRNA misprocessing in cultured Drosophila cells (Wagner et al. 2007). The Act proc $_{\text {reporter, which }}$ specifically detects the efficiency of processing independent of histone gene transcription, contains the Actin 5C promoter driving a portion of the histone ORF and $3^{\prime}$ end processing signal fused to a GFP ORF and followed by a poly(A) site (Fig. 7A). When histone pre-mRNA processing is inhibited or inefficient, RNA polymerase continues past the normal cleavage site and through the GFP ORF, resulting in the production of GFP that can be detected by fluorescence microscopy or Western blot. To increase the reproducibility of these experiments, this reporter was stably integrated into Drosophila D.Mel-2 cells. Knocking down dFLASH by RNA interference results in robust activation of this reporter as well as misprocessing of the endogenous histone mRNAs (Yang et al. 2009).

We adapted the reporter assay to determine the regions of dFLASH required for histone pre-mRNA processing by knocking down the endogenous dFLASH using RNAi and rescuing the inefficient processing by expressing RNAiresistant dFLASH. RNAi-mediated knockdown of mRNAs in Drosophila cells typically involves the use of long dsRNAs that become processed inside the cell into multiple 21-nt siRNAs. Because these dsRNAs are optimally several hundred nucleotides long, constructing RNAi-resistant genes that do not contain the targeted sequences in order to rescue knockdown is difficult. The $3^{\prime}$ UTR is a logical RNAi target to distinguish endogenous from transfected genes, but the dFLASH $3^{\prime}$ UTR is only $\sim 25 \mathrm{nt}$ long, and the $\mathrm{C}$-terminal region of the protein is required for localization to the HLB. Since the first 64 amino acids of dFLASH are not essential for HLB localization and, based upon our observation that this region is not required for processing in vitro in mammalian cells (Yang et al. 2011), we hypothesized that this region of dFLASH might not be required for processing in Drosophila cultured cells. We, therefore, synthesized a dsRNA targeting the $192 \mathrm{nt}$ that encode amino acids 1-64 of dFLASH. This dsRNA activated the $\mathrm{Act}_{\text {proc }}$ reporter (Fig. $7 \mathrm{~B}$ ) as effectively as longer FLASH dsRNAs.

We tested the ability of a dFLASH deletion mutant protein lacking the first 64 amino acids to rescue misprocessing. We transfected D.Mel-2 cells containing the Act $_{\text {proc }}$ reporter with a construct encoding dFLASH 65844, immediately treated the cells with dsRNA, and then imaged the cells two days later. Expression of the dFLASH 65-844 protein "rescued" the misprocessing (Fig. 7B), since it prevented activation of the reporter that normally results from depletion of the endogenous FLASH. Combined with our observation that this protein effectively localizes to the HLB (Supplemental Fig. S1), this result demonstrates that the 65-844 dFLASH protein contains all elements necessary for efficient processing of histone mRNA in vivo and for localization of the protein to the HLB.

\section{$A$ region upstream of the $d \mathrm{Lsm} 11$ binding site is required for histone pre-mRNA processing in Drosophila cultured cells}

We then tested which regions of the $\mathrm{N}$ terminus of FLASH were essential for processing. Deletions of the $\mathrm{N}$ terminus that removed either 77 or 165 amino acids were tested. The 78-844 FLASH binds Lsm11, while the 166-844 protein does not. The dFLASH 78-844 protein did not rescue the RNAi knockdown of FLASH but instead enhanced the activity of the reporter (Fig. 7B). Transfection of cells with the FLASH 166-844 construct, which is missing the N-terminal 165 amino acids that include the dLsm11 binding domain, also does not rescue the misprocessing of the reporter caused by depletion of endogenous dFLASH but, unlike the dFLASH 78-844 protein, did not enhance the activity of the reporter (Fig. 7B). The dFLASH 78-844 protein might inhibit processing by acting in a dominant negative manner, which results in further activation of the reporter above the activation due to dFLASH depletion.

We tested several mutant dFLASH proteins in the cell line containing the Act $_{\text {proc }}$ reporter without RNAi-mediated depletion of endogenous dFLASH to see if their expression inhibited processing of the reporter (Fig. 7C). Expression of full-length dFLASH (1-844) or dFLASH 65844 had no effect on the reporter (Fig. 7C). In contrast, expression of dFLASH 78-844 resulted in significant fluorescence from the reporter (Fig. 7C), indicating that the expression of a dFLASH protein lacking amino acids 1-77 inhibits histone pre-mRNA processing in vivo in the presence of endogenous wild-type dFLASH. Importantly, this protein also localizes to the HLB (Supplemental Fig. S1) and contains the necessary sequences for binding dLsm11 (Fig. 1). In contrast, the 166-844 FLASH, which lacks the dLsm 11 binding site, had no effect on the reporter 
A

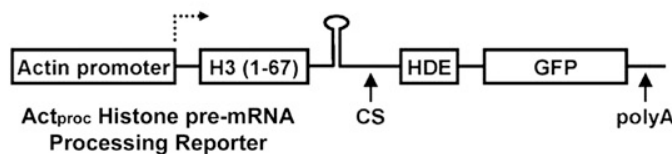

Processing Reporter
C

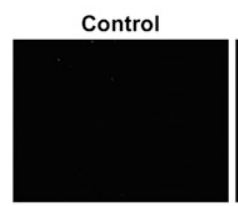

dFLASH

1-169

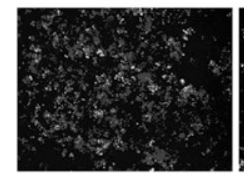

dFLASH

$1-844$

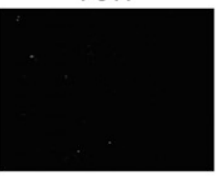

dFLASH

1-154

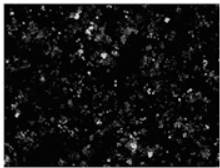
65-844
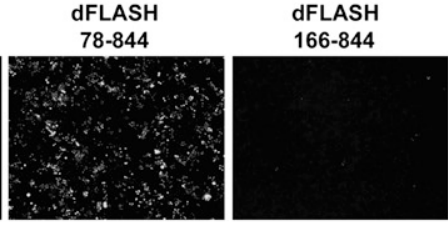

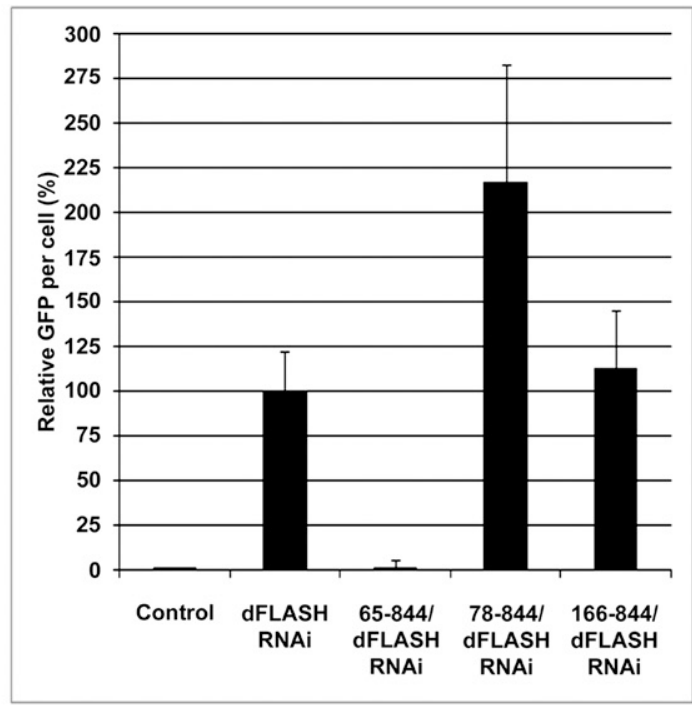

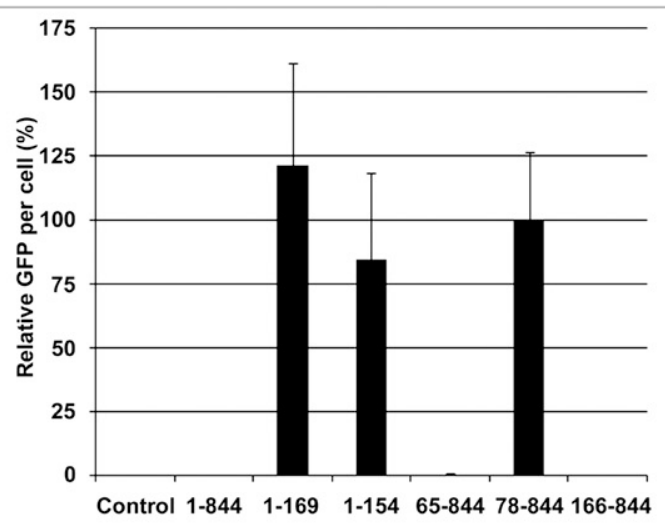

D

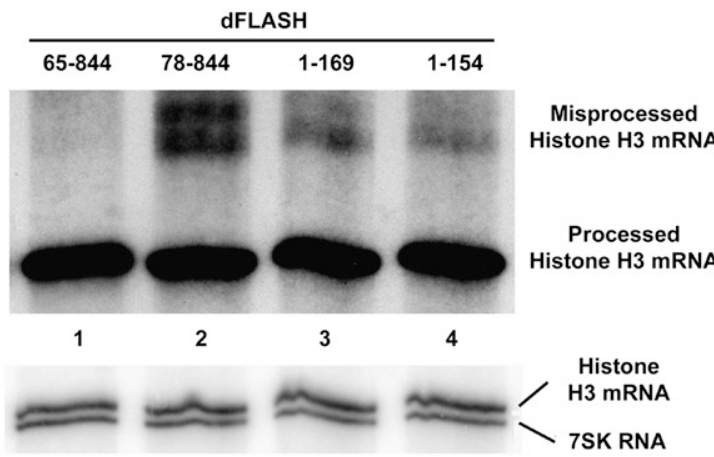

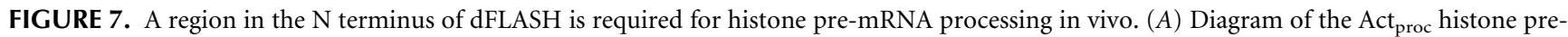
mRNA processing reporter construct that was stably integrated into the Drosophila D.Mel-2 cell line. The construct is driven by the Actin 5C promoter and includes a partial histone H3 ORF (AA1-67) and histone pre-mRNA processing signals, followed by an in-frame GFP ORF and an OpIE2 polyadenylation signal. CS = histone H3 pre-mRNA cleavage site. (B) Diagram of dFLASH, indicating the sites of deletions. AR indicates an activation domain and LBR the Lsm11 binding site, both of which are required for processing. Cells containing the GFP-based reporter were transfected with the indicated constructs and treated with dsRNA, targeting the first $192 \mathrm{nt}$ (corresponding to the first 64 amino acids) of dFLASH or targeting PTB, a factor unrelated to histone pre-mRNA processing (control). Cells were viewed on a fluorescence microscope after $2 \mathrm{~d}$. Representative images are shown. The bar graph shows the relative fluorescence per cell and represents data from three random fields taken from two independent experimental wells. (C) Drosophila D.Mel-2 reporter cells were transfected with the indicated constructs and viewed on a fluorescence microscope after $2 \mathrm{~d}$. Representative images are shown. The bar graph shows the relative fluorescence per cell and represents data from three random fields taken from two independent experimental wells. $(D)$ Northern blot analysis of total RNA from D.Mel-2 cells transfected with the constructs in panel $C$ using a probe targeting histone $\mathrm{H} 3$ (top). The blot was then reprobed (without stripping) for 7SK RNA as a loading control (bottom). 
(Fig. 7C), although it still localized to the HLB (Figs. 5B and $6 \mathrm{C}$ ). These two proteins were expressed to similar levels based on the intensity of the fluorescence and Western blots (Supplemental Fig. S4). Together, these results suggest that the dFLASH 78-844 mutant protein is a dominant negative due to its binding endogenous dLsm11 and forming an inactive complex within the HLB. Further, these data suggest that residues between amino acids 65 and 77 of dFLASH bind a factor necessary for processing. A complex containing dFLASH AA78-844 bound to Lsm11/U7 snRNP would not be able to bind this factor, and processing would be inhibited (Fig. 8).

We have previously observed that the first 139 amino acids of mammalian FLASH, including the Lsm11 binding site, are necessary and sufficient to support processing of histone pre-mRNA in nuclear extracts (Yang et al. 2009). Since proteins containing only the $\mathrm{N}$-terminal region of the dFLASH protein do not localize efficiently to the HLB (Fig. 5C), we tested whether these proteins would have any effect on the Act $_{\text {proc }}$ reporter in cultured cells. We expressed mutant FLASH proteins 1-154 and 1-169, both of which can bind Lsm11. Both proteins activated the reporter (Fig. 7C) and thus also function as dominant negatives in vivo. These proteins accumulate to higher levels than the larger FLASH proteins, based on both the fluorescence and Western blots (Supplemental Fig. S4). Because the majority of these proteins are in the nucleoplasm (Fig. 5C), it is possible that these proteins bind U7 snRNP in the nucleoplasm and prevent it from being recruited effectively to FLASH in the HLB (Fig. 8).

We used Northern blotting to determine whether the mutant dFLASH proteins that activated the Act $_{\text {proc }}$ reporter also inhibited processing of the endogenous histone mRNAs. Similar to the reporter data, expression of the dFLASH 78844 mutant protein resulted in the production of misprocessed histone mRNA (Fig. 7D, lane 2), while expression of the dFLASH 65-844 mutant protein did not (Fig. 7D, lane 1). The levels of misprocessed endogenous histone mRNA are small, both because there are normal amounts of endogenous dFLASH and not all the cells are transfected with the FLASH mutants. Note that even in RNAi experiments for SLBP or FLASH, which show $>90 \%$ knockdown, there are still substantial amounts of properly processed mRNA (Yang et al. 2009), and complete loss of processing is only seen in null mutants for SLBP or U7 snRNP (Godfrey et al. 2006). Expression of the dFLASH 1-169 and 1-154 mutant proteins also resulted in a small amount of unprocessed histone mRNA (Fig. 7D, lanes 3,4), although the amount of misprocessed histone mRNA was lower than in the dFLASH 78-844-expressing cells. These proteins do not effectively localize to the HLB (Fig. 5C) and thus are likely inefficient at competing with endogenous dFLASH. In contrast to the other mutants, expression of the dFLASH 166-844 protein, which lacks the entire region required for histone pre-mRNA processing in vitro, did not result in any

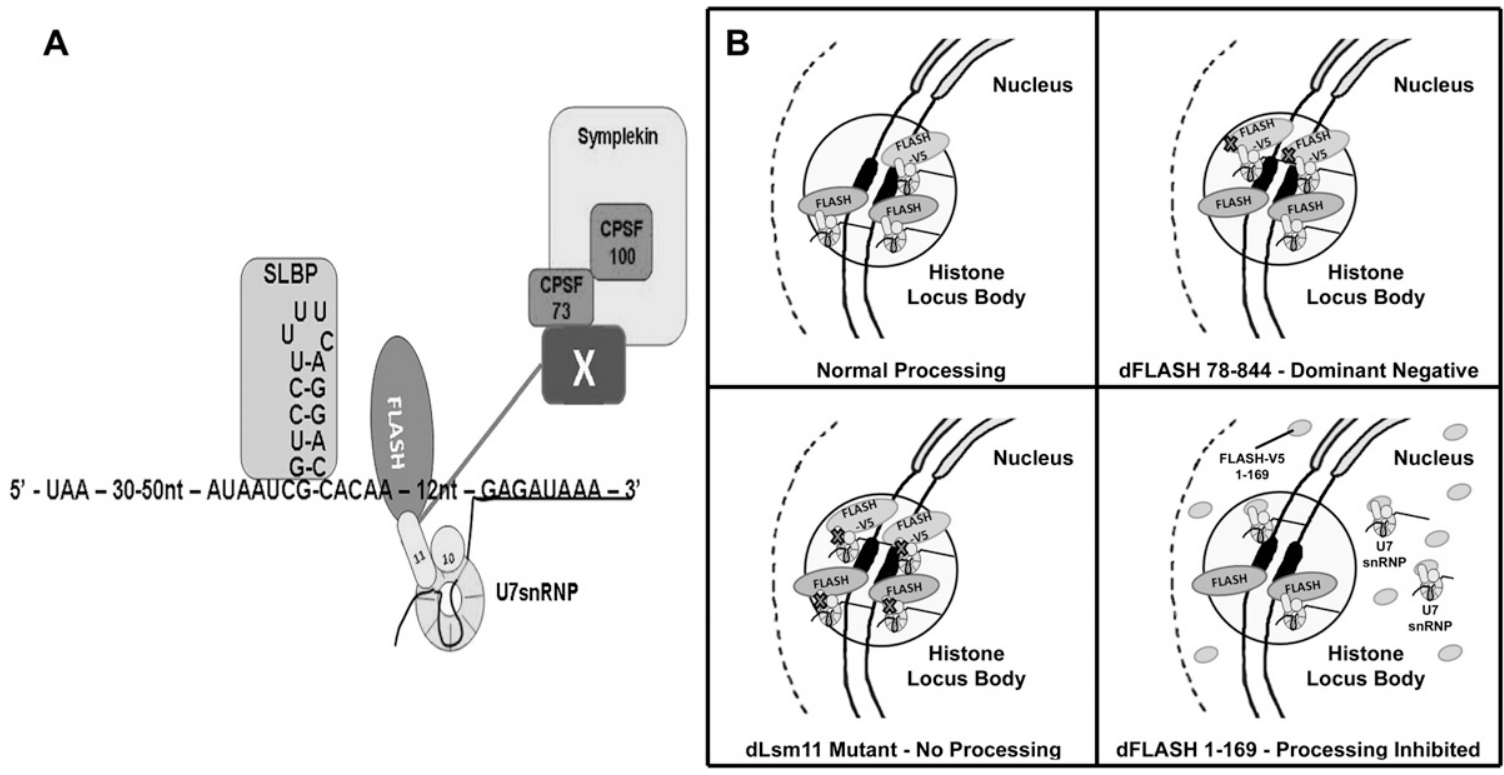

FIGURE 8. Model for FLASH function. (A) The current model for histone pre-mRNA processing in vitro. This reaction only requires the N terminus of FLASH, and the Lsm11/FLASH complex is postulated to recruit a novel factor that is part of the histone pre-mRNA cleavage factor (Yang et al. 2011). (B) Histone pre-mRNA processing in vivo. The histone locus is located on chromosome $2 \mathrm{~L}$ adjacent to a heterochromatic region. The HLB contains both Lsm11 and FLASH, which interact with each other (top left) and are critical for histone pre-mRNA processing in vivo. In the mutant of Lsm11 that does not bind FLASH, both U7 snRNP and FLASH are in the HLB, but there is no processing of histone mRNA (bottom left). The FLASH mutants that localize to the HLB and can bind Lsm11, but not factor X (panel $A$ ), act as dominant negatives for processing (upper right). Expression of FLASH fragments that bind Lsm11 and are largely present in the nucleoplasm can reduce the Lsm11 concentration in the HLB, resulting in a mild inhibition of processing (bottom right). 
misprocessed endogenous histone mRNA (Supplemental Fig. S3). Together, these results confirm the reporter data and reveal that the dFLASH 78-844 protein acts as a dominant negative for histone pre-mRNA processing on both the reporter and the endogenous histone genes and, further, that this inhibition is dependent upon the presence of an intact Lsm11 binding site.

\section{DISCUSSION}

FLASH is a component of the HLB (Bongiorno-Borbone et al. 2008) and is essential for histone pre-mRNA processing in vitro and in vivo (Yang et al. 2009). FLASH interacts with the amino terminus of Lsm11, and in this work we have defined the amino acids required for this interaction in Drosophila. FLASH interacts with the most evolutionarily conserved region in Lsm11, and a number of small mutations between amino acids 20 and 34 in dLsm11 disrupt binding to dFLASH. The pattern of required amino acids is striking, with mutation of two patches (L20A/ $\mathrm{D} 21 \mathrm{~A} / \mathrm{V} 22 \mathrm{~A}$ and $\mathrm{F} 27 \mathrm{~A} / \mathrm{N} 28 \mathrm{~A}$ ) causing complete loss of binding, mutation of the LY residues at positions 33-34 weakening the binding interaction, and mutation of intervening conserved residues (S24A/D25A, P29A/L30A, or P36A/N37A) having no effect on binding. This is suggestive of an $\alpha$-helical domain structure that has been predicted for the $\mathrm{N}$ terminus of Lsm11 (Azzouz and Schümperli 2003), and these results are consistent with findings for human Lsm11, which requires a similar pattern of conserved residues in this region to bind human FLASH efficiently (Yang et al. 2011). Although the region between amino acids 20 and 34 of dLsm11 is essential for binding, it is not sufficient to bind dFLASH. Indeed, the smallest dLsm11 protein we tested that is capable of binding dFLASH contains amino acids 1-78. We speculate that these additional amino acids are required for forming the proper structure of the $\mathrm{N}$ terminus of dLsm11, and/or that they make additional contacts with dFLASH that stabilize binding.

Using a similar approach, we identified a region in the $\mathrm{N}$ terminus of dFLASH that is required for binding dLsm 11 . An $\sim 50$-amino acid-region of dFLASH (AA105-154), which is the most conserved region between dFLASH and human FLASH, is essential for binding dLsm11. In addition, we find that mutation of the NL residues at positions 125-126 or the LL residues at positions 129-130 blocks binding with dLsm11. A similar region in human FLASH is required for binding human Lsm11 (Yang et al. 2011).

We had previously isolated Drosophila Lsm10 and Lsm11 null mutants and found that these mutants produce only polyadenylated histone mRNA as third instar larvae but die as nonpharate pupae, failing to eclose (Godfrey et al. 2009). U7 null mutants produce only polyadenylated histone mRNA as third instar larvae; however, these mutants develop into adult flies that are sterile (Godfrey et al. 2006). These results suggested that the lethality of the
Lsm10 and Lsm11 mutant flies does not arise solely from polyadenylation of histone mRNA and led to the proposal that Lsm10 and Lsm11 may have an essential function outside of histone pre-mRNA processing (Godfrey et al. 2009). Since dFLASH is required for histone pre-mRNA processing, it was possible that we could uncouple the role of Lsm11 in histone pre-RNA processing from other putative essential functions by creating point mutations that prevent binding of Lsm11 to dFLASH. However, we instead found that the dFLASH binding site on dLsm11 is essential, not only for histone pre-mRNA processing but also for viability in flies. While these results do not directly refute the model proposed by Godfrey et al. (2009), they do suggest that, if there is an essential function for dLsm10 and dLsm11 outside of histone pre-mRNA processing, this function requires the region of dLsm11 that interacts with FLASH.

\section{Requirements for FLASH localization to the HLB}

FLASH localizes near the histone genes in both mammals and flies within a subnuclear organelle known as the histone locus body (HLB) (Liu et al. 2006a; BongiornoBorbone et al. 2008; Yang et al. 2009). However, it is not known how dFLASH or other components of the HLB (or of other nuclear bodies) are brought together. Our results define sequences in dFLASH that are necessary for localizing the protein to the nucleus and the HLB. Removal of the last 45 amino acids of dFLASH prevents efficient localization to the HLB, and this C-terminal region is the most critical for HLB localization. Proteins that lack these 45 amino acids but contain the first 170 amino acids of dFLASH were present throughout the nucleoplasm with only a weak concentration at the HLB, demonstrating that the Lsm11 binding site alone is not capable of efficiently directing HLB localization. Supporting this finding, deletion of the Lsm11 binding site (166-844) had only a small effect on the localization of the protein to the HLB, demonstrating that the primary HLB localization sequence lies within the $\mathrm{C}$ terminus. These results are consistent with our findings that dFLASH localizes normally to the HLB in Lsm11 null flies, and together, the data reveal that dLsm11 is not responsible for recruiting dFLASH to the HLB, although it may lend some stability to its association there.

Removal of both the Lsm11 binding site together with the C-terminal 45 amino acids from dFLASH (166-799) resulted in a totally nucleoplasmic distribution of the protein with no detectable concentration at the HLB, demonstrating that the Lsm11 binding site assists in the concentration of FLASH in the HLB. Further deletion of the $C$ terminus (166-757) resulted in exclusion of the protein from the nucleus, indicating the presence of a nuclear localization signal between amino acids 758 and 799, in addition to one at the $\mathrm{N}$ terminus of the protein. A minimal dFLASH protein, consisting of amino acids $1-178$ fused directly to amino acids $726-844$, localized to the HLB as efficiently as full length dFLASH. 
These results highlight the significance of the $\mathrm{C}$ terminus of dFLASH for localization to the HLB. They are in agreement with studies of mammalian FLASH that the $\mathrm{C}$ terminus of FLASH is required for coimmunoprecipitation with NPAT (Kiriyama et al. 2009), an important regulator of histone expression that localizes to the HLB (Barcaroli et al. 2006a; Bongiorno-Borbone et al. 2008), suggesting a mechanism for localization to the HLB. There is no discernable sequence homology between the $\mathrm{C}$ terminus of dFLASH and mammalian FLASH, suggesting that if an interaction with NPAT is evolutionarily conserved, the sequences have diverged substantially. It is likely that, like mammalian FLASH, dFLASH is involved in functions in addition to histone premRNA processing (Imai et al. 1999; Choi et al. 2001; Kino et al. 2004; Kiriyama et al. 2009) and that the central portion of the protein is important for these roles.

\section{Requirements for histone pre-mRNA processing in vivo}

Using a reporter system that detects defective histone premRNA processing, we were able to test the function of different FLASH constructs in processing in vivo. Surprisingly, we found two classes of FLASH mutants that inhibited processing, acting as dominant negatives in vivo in the presence of wild-type FLASH. One contained a deletion of amino acids upstream of the dLsm11 binding site. This protein, 78-844, was incorporated into the HLB, activated the reporter, and resulted in misprocessing of endogenous histone mRNA, most likely by sequestering the dU7 snRNP in an inactive complex at the HLB (Fig. 8B). These results suggest that there is an activation region between amino acids 65 and 100, which includes several conserved residues, that is critical for processing. This region likely binds an unknown processing factor, possibly to help recruit the cleavage factor (Sullivan et al. 2009). Similar conclusions have been reached from biochemical analysis of the human FLASH protein (Yang et al. 2011).

The other class of inhibitors was two small proteins containing amino acids 65-154, containing the activation region as well as the Lsm11 binding site, which also activated the misprocessing reporter. dFLASH 1-154 and 1-169 bind dLsm11 but are not effectively localized to the HLB. They had a small inhibitory effect on the processing of the endogenous histone mRNA. The lesser effect on endogenous histone mRNA compared to that of the dFLASH 78-844 protein is likely because these proteins do not localize efficiently to the HLB, which contains normal amounts of endogenous dFLASH. It is possible that these shorter truncated dFLASH proteins bind a pool of some essential processing factor, possibly the dU7 snRNP, reducing its concentration in the HLB (Fig. 8B).

These results suggest a model for histone pre-mRNA processing in vivo (Fig. 8). dFLASH contains a sequence at the N-terminus that is required for binding dLsm11 and which may help stabilize the association of dFLASH at the HLB. dFLASH also contains sequences at its $\mathrm{C}$ terminus that are required for proper localization to the HLB. Exactly how these sequences participate in the recruitment and retention of dFLASH to the HLB is unknown, but it seems likely that dFLASH makes contact with one or more HLB components in addition to dLsm11. Finally, there is a third element in FLASH between amino acids 65 and the Lsm11 binding site that is required for histone pre-mRNA processing in vivo and likely binds another processing factor. The ability to readily test putative factors that can affect histone mRNA processing in vivo will help us understand the role of the HLB in histone mRNA biosynthesis, which likely involves coordinating histone gene transcription and processing.

\section{MATERIALS AND METHODS}

\section{Plasmid construction}

Constructs encoding wild-type and mutant dFLASH or dLsm11 proteins N-terminally fused to gluthione S-tranferase (GST) were created using EcoRI and XhoI to clone into the pET42a vector. In vitro transcription/translation constructs were created using EcoRI and XhoI to subclone these sequences into the pOT2 vector, which contains a T7 promoter.

Expression constructs for transfection into Drosophila D.Mel-2 cultured cells were created by inserting the dFLASH promoter into the promoterless $\mathrm{pIZ/V5/His} \mathrm{vector,} \mathrm{followed} \mathrm{by} \mathrm{subcloning} \mathrm{a} \mathrm{full}$ or partial dFLASH ORF into this construct. The endogenous dFLASH promoter and 5' UTR were amplified by PCR from genomic DNA using primers targeting the entire genomic region between the upstream gene, latheo (dORC3), and the start codon of dFLASH. This region consists of a putative promoter of $233 \mathrm{nt}$ followed by $336 \mathrm{nt}$ containing the dFLASH $5^{\prime}$ UTR up to the start codon of the ORF. This promoter/5' UTR sequence was cloned into the promoterless $\mathrm{pIZ/V5/His} \mathrm{gene} \mathrm{resulting} \mathrm{in} \mathrm{the} \mathrm{pIZ/}$ FLASHp/V5/His construct. Portions of the dFLASH ORF were subcloned into this construct using EcoRI and SacII. The resulting construct contained the dFLASH promoter driving expression of a full length or truncated dFLASH ORF followed by an in-frame V5 epitope sequence.

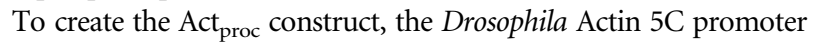
was amplified from genomic DNA by PCR and cloned into the pIZ/ promoterless/H3/GFP plasmid using HindIII and EcoRI. The resulting Act $_{\text {proc }}$ reporter gene consisted of the Actin $5 \mathrm{C}$ promoter followed by the region encoding the first 67 amino acids of Drosophila histone $\mathrm{H} 3$, a portion of the histone H3 $3^{\prime}$ UTR that included the SL and $\mathrm{HDE}$, an in-frame GFP ORF, and a vector-encoded OpIE2 poly(A) signal previously described (Wagner et al. 2007).

\section{Protein purification}

Escherichia coli BL21(DE3) cells were transformed with pET42a plasmid constructs encoding glutathione-S-transferase (GST) fused in frame to wild-type or mutant dFLASH or dLsm11 coding sequences. Liquid cultures were induced in the presence of 0.5 $\mathrm{mM}$ IPTG for $3 \mathrm{~h}$ at $37^{\circ} \mathrm{C}$. Bacterial cell pellets were resuspended 
in $20 \mathrm{~mL}$ lysis buffer (50 mM Tris, $\mathrm{pH} 8.0,5 \mathrm{mM}$ EDTA, $50 \mathrm{mM}$ $\mathrm{NaCl}, 10 \%$ glycerol, $0.5 \% \mathrm{NP}-40$ ), supplemented with $1 \mathrm{mM}$ PMSF and incubated $15 \mathrm{~min}$ at room temperature. The cell suspension was sonicated on ice three times for $20 \mathrm{~s}$. The supernatant was incubated for $4 \mathrm{~h}$ at $4^{\circ} \mathrm{C}$ with $300 \mu \mathrm{L}$ of a $1: 1$ slurry of glutathione-agarose beads (Sigma) pre-equilibrated with lysis buffer. After incubation, the beads were recovered by centrifugation at $300 \times \mathrm{g}$ for $5 \mathrm{~min}$ at $4^{\circ} \mathrm{C}$ and washed three times with 15 $\mathrm{mL}$ cold PBS at $4^{\circ} \mathrm{C}$ for $10 \mathrm{~min}$ per wash. GST-fusion proteins were eluted from the beads by adding $500 \mu \mathrm{L}$ elution buffer $(50 \mathrm{mM}$ Tris, $\mathrm{pH} 8.8,10 \mathrm{mM}$ glutathione) and rotating at $4^{\circ} \mathrm{C}$ for $30 \mathrm{~min}$.

\section{In vitro translation and GST-pulldown experiments}

In vitro translation reactions were performed using a coupled transcription and translation (TNT) kit (Promega) to express a pOT2 plasmid construct containing a T7 promoter sequence driving a FLASH or Lsm11 coding sequence. GST-pulldown assays were performed by combining $7 \mu \mathrm{L}$ in vitro translated protein (IVT) with $5 \mu \mathrm{g}$ GST-fusion protein in a total of $100 \mu \mathrm{L}$ of $1 \times$ binding buffer (15 mM Tris, pH 8.0, $20 \mathrm{mM}$ EDTA, $75 \mathrm{mM} \mathrm{KCl}$, $0.375 \mathrm{mM}$ DTT, $10 \%$ glycerol, $0.1 \% \mathrm{NP}-40$ ). Samples were incubated on ice for $30 \mathrm{~min}$, followed by incubation at room temperature for $30 \mathrm{~min}$. Following incubation, $370 \mu \mathrm{L}$ of $1 \times$ binding buffer and $30 \mu \mathrm{L}$ of a 1:1 slurry of glutathione-agarose beads (Sigma) pre-equilibrated with $1 \times$ binding buffer were added, and the samples were rotated for $1 \mathrm{~h}$ at $4^{\circ} \mathrm{C}$. After incubation, the beads were washed four times with $1 \times$ binding buffer for $10 \mathrm{~min}$ per wash. After the final wash, the beads were boiled for $3 \mathrm{~min}$ in 25 $\mu \mathrm{L}$ SDS loading buffer (100mM Tris-Cl, pH 6.8, $200 \mathrm{mM}$ DTT, 4\% SDS, $20 \%$ glycerol, $0.2 \%$ bromophenol blue), and the samples were loaded onto a $12.5 \%$ or $15 \%$ polyacrylamide gel. Following electrophoresis, the gels were stained with Coomassie stain, dried, and exposed to autoradiography film or a phosphor screen.

\section{dsRNA synthesis and RNA interference}

DNA templates for double stranded RNAs (dsRNAs) were generated by PCR using Drosophila Gene Collection library clones (Open Biosystems) and primers containing a T7 promoter. In vitro transcription was carried out in a total volume of $300 \mu \mathrm{L}$ using the TranscriptAid T7 high yield transcription kit (Fermentas), as recommended by the manufacturer, after which the RNA was treated with 5 units of RNase-free DNase Q (Promega), boiled for 5 min and cooled to room temperature to form dsRNA.

RNA interference was induced in Drosophila D.Mel-2 cultured cells by plating cells to a density of $5 \times 10^{5}$ cells per well of a 24 -well tissue culture plate (Greiner) in $250 \mu \mathrm{L}$ SF-900II SFM (Gibco), adding $5 \mu \mathrm{g}$ dsRNA directly to the medium and incubating the cells at $27^{\circ} \mathrm{C}$ in a humidified growth chamber for $3 \mathrm{~d}$.

\section{RNA purification and Northern blot analysis}

Total RNA was purified from Drosophila D.Mel-2 cultured cells or Drosophila larvae using Trizol reagent (Invitrogen), according to the manufacturer's protocol. Northern blot analysis of these RNAs was used to detect histone H3 mRNA. Briefly, the RNAs were separated on a $6 \%$ polyacrylamide/7M urea gel, followed by transfer of the resolved RNAs to a Hybond-N+ membrane (Amersham Biosciences). Drosophila histone H3 mRNA was detected using a ${ }^{32} \mathrm{P}$-labeled probe, with a probe targeting 7SK RNA used as a loading control.

\section{Cell transfections and processing reporter assays}

Drosophila D.Mel-2 cultured cells were maintained in SF-900II SFM (Gibco) without serum at $27^{\circ} \mathrm{C}$ in a humidified growth chamber. Transfection of plasmid constructs was performed using the Amaxa Nucleofector electroporation system (Lonza) and the Nucleofector V kit (Lonza) according to the manufacturer's protocol for the Drosophila S2 cell line.

For rescue experiments, Drosophila D.Mel-2 cells stably expressing the $\mathrm{Act}_{\text {proc }}$ reporter were transfected with pIZ/ FLASHp/FLASH $\mathrm{ORF}_{\mathrm{O}} / \mathrm{V} 5 / \mathrm{His}$ constructs, immediately treated with dsRNAs, and incubated for $3 \mathrm{~d}$ before viewing on an Olympus IX81-ZDC inverted fluorescence microscope.

\section{Immunofluorescence}

Drosophila D.Mel-2 cells transfected with pIZ/FLASHp/FLA$\mathrm{SH}_{\mathrm{ORF}} / \mathrm{V} 5$ plasmid constructs were plated onto laminin-coated glass coverslips (BD Biosciences) on Day 2 post-transfection. Once they adhered, the cells were rinsed with PBS, fixed with $4 \%$ paraformaldehyde in PBS for $10 \mathrm{~min}$ at room temperature, rinsed again with PBS, and permeabilized with $0.1 \%$ Triton X-100 (Sigma) in PBS for $30 \mathrm{~min}$. The cells were then washed three times with $0.1 \%$ Triton X-100 in PBS for 1 min per wash, followed by blocking with $5 \%$ normal goat serum (Sigma) in PBS for 30 min. Primary antibodies diluted in 5\% normal goat serum in PBS (anti-V5 1:500; anti-Mxc 1:500; anti-Mute 1:2000) were applied to the coverslip, followed by incubation at room temperature for $1 \mathrm{~h}$. After incubation, the coverslips were washed with $0.1 \%$ Triton $\mathrm{X}-100$ in PBS three times for 10 min per wash. Next, the coverslips were incubated with a solution of $5 \%$ normal goat serum in PBS containing appropriate secondary antibodies diluted 1:5000, followed by incubation at room temperature for $1 \mathrm{~h}$. The coverslips were washed with $0.1 \%$ Triton X-100 in PBS three times for 10 min per wash and once in PBS for $1 \mathrm{~min}$. The cells were stained with DAPI diluted to $0.5 \mu \mathrm{g} / \mathrm{mL}$ in PBS for $5 \mathrm{~min}$ at room temperature, followed by three brief washes with PBS. The coverslips were mounted onto microscope slides using Crystal/Mount mounting medium (Biomeda Corp.), allowed to dry, and viewed using a Zeiss LSM 710 confocal microscope at $630 \times$ magnification.

For staining of larval salivary glands, salivary glands were dissected from wandering third instar larvae, fixed in 3.7\% formaldehyde in PBS plus 1\% Triton X-100 for 15 min and blocked in $0.1 \%$ Triton X-100 in PBS containing 5\% normal goat serum. The tissue was incubated with primary antibodies overnight at $4^{\circ} \mathrm{C}$ at the following concentrations: $\alpha$-V5 1:1000; $\alpha$-dFLASH 1:500; and $\alpha$-Mute (Bulchand et al. 2010) 1:2000. The tissue was incubated with secondary antibodies at room temperature for $1 \mathrm{~h}$ at the following concentrations: mouse $\alpha-\mathrm{Cy} 3$ (Jackson Labs) 1:500; rabbit $\alpha$-Alexafluor488 (Invitrogen) 1:2000; and guinea pig $\alpha$-Cy5 (Jackson Labs) 1:2000. Tissues were stained with DAPI and imaged on a Zeiss 510 confocal microscope.

\section{Drosophila genetics}

Wild-type and mutant V5-Lsm11 open reading frames expressed using the endogenous Lsm11 promoter (Godfrey et al. 2009) were 
cloned into the pattB vector, a derivative of the $\mathrm{pUASTattB}$ vector that has the UAS-MCS-SV40 cassette replaced by a multiple cloning site only (Bischof et al. 2007). Transgenic lines (BestGene Inc.) were generated by targeting these constructs to attP site $22 \mathrm{~A} 3$ on chromosome 2 (Bischof et al. 2007). Phenotypic rescue experiments were performed with recombinant chromosomes that contain these V5-Lsm11 transgenes and the null $\operatorname{Lsm} 11^{\mathrm{C} 02047}$ allele (Godfrey et al. 2009). RNA analysis was performed with samples collected from attP[V5-Lsm11], Lsm11 ${ }^{\text {C02047 }}$ homozygous mutant larvae, and experiments to assess rescue of Lsm11 mutant lethality were performed with attP[V5-Lsm11], Lsm11 ${ }^{\mathrm{C} 02047}$ / Df(2R)M073 progeny (Godfrey et al. 2009).

\section{SUPPLEMENTAL MATERIAL}

Supplemental material is available for this article.

\section{ACKNOWLEDGMENTS}

This work was supported by NIH grant GM58921 to W.F.M. and Z.D. and grant GM57859 to R.J.D. We thank Xiao-Cui Yang and Bing Xu for excellent technical assistance. We thank BestGene Inc. (Chino Hills, CA) for advice on insertion sites for transgenesis.

Received November 26, 2010; accepted March 7, 2011.

\section{REFERENCES}

Azzouz TN, Schümperli D. 2003. Evolutionary conservation of the U7 small nuclear ribonucleoprotein in Drosophila melanogaster. RNA 9: 1532-1541.

Azzouz TN, Gruber A, Schümperli D. 2005. U7 snRNP-specific Lsm11 protein: Dual binding contacts with the $100 \mathrm{kDa}$ zinc finger processing factor (ZFP100) and a ZFP100-independent function in histone RNA 3' end processing. Nucleic Acids Res 33: 2106-2117.

Barcaroli D, Bongiorno-Borbone L, Terrinoni A, Hofmann TG, Rossi M, Knight RA, Matera AG, Melino G, De Laurenzi V. 2006a. FLASH is required for histone transcription and S-phase progression. Proc Natl Acad Sci 103: 14808-14812.

Barcaroli D, Dinsdale D, Neale MH, Bongiorno-Borbone L, Ranalli M, Munarriz E, Sayan AE, McWilliam JM, Smith TM, Fava E, et al. 2006b. FLASH is an essential component of Cajal bodies. Proc Natl Acad Sci 103: 14802-14807.

Bischof J, Maeda RK, Hediger M, Karch F, Basler K. 2007. An optimized transgenesis system for Drosophila using germ-linespecific phiC31 integrases. Proc Natl Acad Sci 104: 3312-3317.

Bongiorno-Borbone L, De Cola A, Vernole P, Finos L, Barcaroli D, Knight RA, Melino G, De Laurenzi V. 2008. FLASH and NPAT positive but not Coilin positive Cajal Bodies correlate with cell ploidy. Cell Cycle 7: 2357-2367.

Bulchand S, Menon SD, George SE, Chia W. 2010. Muscle wasted: A novel component of the Drosophila histone locus body required for muscle integrity. J Cell Sci 123: 2697-2707.

Choi YH, Kim KB, Kim HH, Hong GS, Kwon YK, Chung CW, Park YM, Shen ZJ, Kim BJ, Lee SY, et al. 2001. FLASH coordinates NFкB activity via TRAF2. J Biol Chem 276: 25073-25077.

Dominski Z, Yang XC, Marzluff WF. 2005. The polyadenylation factor CPSF-73 is involved in histone pre-mRNA processing. Cell 123: $37-48$.

Ghule PN, Dominski Z, Yang XC, Marzluff WF, Becker KA, Harper JW, Lian JB, Stein JL, Van Wijnen AJ, Stein GS. 2008. Staged assembly of histone gene expression machinery at subnuclear foci in the abbreviated cell cycle of human embryonic stem cells. Proc Natl Acad Sci 44: 16964-16969.
Godfrey AC, Kupsco JM, Burch BD, Zimmerman RM, Dominski Z, Marzluff WF, Duronio RJ. 2006. U7 snRNA mutations in Drosophila block histone pre-mRNA processing and block oogenesis. RNA 12: 396-409.

Godfrey AC, White AE, Tatomer DC, Marzluff WF, Duronio RJ. 2009. The Drosophila U7 snRNP proteins Lsm10 and Lsm11 play an essential role in development independent of histone pre-mRNA processing. RNA 15: 1661-1672.

Groth AC, Fish M, Nusse R, Calos MP. 2004. Construction of transgenic Drosophila by using the site-specific integrase from phage phiC31. Genetics 166: 1775-1782.

Imai Y, Kimura T, Murakami A, Yajima N, Sakamaki K, Yonehara S. 1999. The CED-4-homologous protein FLASH is involved in Fasmediated activation of caspase-8 during apoptosis. Nature 398: $777-785$.

Isogai Y, Keles S, Prestel M, Hochheimer A, Tjian R. 2007. Transcription of histone gene cluster by differential core-promoter factors. Genes Dev 21: 2936-2949.

Kino T, Ichijo T, Chrousos GP. 2004. FLASH interacts with p160 coactivator subtypes and differentially suppresses transcriptional activity of steroid hormone receptors. J Steroid Biochem Mol Biol 92: $357-363$.

Kiriyama M, Kobayashi Y, Saito M, Ishikawa F, Yonehara S. 2009. Interaction of FLASH with arsenite resistance protein 2 is involved in cell cycle progression at S phase. Mol Cell Biol 29: 4729-4741.

Kolev NG, Steitz JA. 2005. Symplekin and multiple other polyadenylation factors participate in $3^{\prime}$-end maturation of histone mRNAs. Genes Dev 19: 2583-2592.

Kolev NG, Yario TA, Benson E, Steitz JA. 2008. Conserved motifs in both CPSF73 and CPSF100 are required to assemble the active endonuclease for histone mRNA 3 '-end maturation. EMBO Rep 10: 1013-1018.

Lanzotti DJ, Kaygun H, Yang X, Duronio RJ, Marzluff WF. 2002. Developmental control of histone mRNA and dSLBP synthesis during Drosophila embryogenesis and the role of dSLBP in histone mRNA 3' processing in vivo. Mol Cell Biol 22: 22672282.

Lifton RP, Goldberg ML, Karp RW, Hogness DS. 1978. The organization of the histone genes in Drosophila melanogaster: Functional and evolutionary implications. Cold Spring Harb Symp Quant Biol 42: 1047-1051.

Liu JL, Buszczak M, Gall JG. 2006a. Nuclear bodies in the Drosophila germinal vesicle. Chromosome Res 14: 465-475.

Liu JL, Murphy C, Buszczak M, Clatterbuck S, Goodman R, Gall JG. 2006b. The Drosophila melanogaster Cajal body. J Cell Biol 172: $875-884$.

Marzluff WF, Wagner EJ, Duronio RJ. 2008. Metabolism and regulation of canonical histone mRNAs: Life without a poly(A) tail. Nat Rev Genet 9: 843-854.

Mowry KL, Steitz JA. 1987. Identification of the human U7 snRNP as one of several factors involved in the $3^{\prime}$ end maturation of histone premessenger RNA's. Science 238: 1682-1687.

Pillai RS, Will CL, Lührmann R, Schümperli D, Müller B. 2001. Purified U7 snRNPs lack the Sm proteins D1 and D2 but contain Lsm10, a new $14 \mathrm{kDa} S m$ D1-like protein. EMBO J 20: 54705479.

Pillai RS, Grimmler M, Meister G, Will CL, Luhrmann R, Fischer U, Schumperli D. 2003. Unique Sm core structure of U7 snRNPs: Assembly by a specialized SMN complex and the role of a new component, Lsm11, in histone RNA processing. Genes Dev 17: 2321-2333.

Sullivan E, Santiago C, Parker ED, Dominski Z, Yang X, Lanzotti DJ, Ingledue TC, Marzluff WF, Duronio RJ. 2001. Drosophila stem-loop binding protein coordinates accumulation of mature histone mRNA with cell cycle progression. Genes Dev 15: 173187.

Sullivan KD, Steiniger M, Marzluff WF. 2009. A core complex of CPSF73, CPSF100 and symplekin may form two different cleavage 
factors for processing of poly(A) and histone mRNAs. Mol Cell 34: 322-332.

Wagner EJ, Burch BD, Godfrey AC, Salzer HR, Duronio RJ, Marzluff WF. 2007. A genome-wide RNA interference screen reveals that variant histones are necessary for replication-dependent histone pre-mRNA processing. Mol Cell 28: 692-699.

White AE, Burch BD, Yang XC, Gasdaska PY, Dominski Z, Marzluff WF, Duronio RJ. 2011. Drosophila histone locus bodies form by hierarchical recruitment of components. J Cell Biol (in press).
Yang XC, Burch BD, Yan Y, Marzluff WF, Dominski Z. 2009. FLASH, a proapoptotic protein involved in activation of caspase- 8 , is essential for $3^{\prime}$ end processing of histone pre-mRNAs. Mol Cell 36: 267-278.

Yang XC, Xu B, Sabath I, Kunduru L, Burch BD, Marzluff WF, Dominski Z. 2011. FLASH is required for the endonucleolytic cleavage of histone pre-mRNAs but is dispensable for the $5^{\prime}$ exonucleolytic degradation of the downstream cleavage product. Mol Cell Biol 31: 1492-1502. 

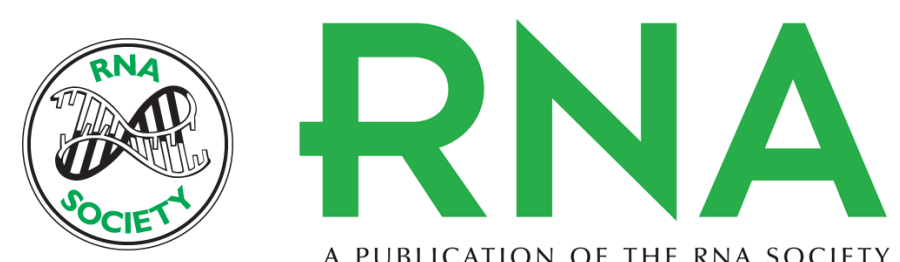

A PUBLICATION OF THE RNA SOCIETY

\section{Interaction between FLASH and Lsm11 is essential for histone pre-mRNA processing in vivo in Drosophila}

Brandon D. Burch, Ashley C. Godfrey, Pamela Y. Gasdaska, et al.

RNA 2011 17: 1132-1147 originally published online April 27, 2011

Access the most recent version at doi:10.1261/rna.2566811

\section{Supplemental http://rnajournal.cshlp.org/content/suppl/2011/04/06/rna.2566811.DC1 \\ Material}

References This article cites 32 articles, 19 of which can be accessed free at: http://rnajournal.cshlp.org/content/17/6/1132.full.html\#ref-list-1

\section{License}

Email Alerting Receive free email alerts when new articles cite this article - sign up in the box at the Service top right corner of the article or click here.

\section{III!"II Providing Precise Solutions tor your research.}

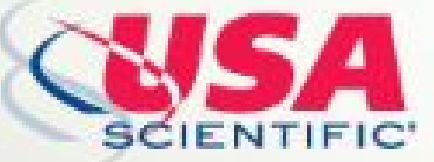

To subscribe to $R N A$ go to:

http://rnajournal.cshlp.org/subscriptions 